\title{
Jaqueline Beppler
}

\section{Identificação de peptídeos de Escherichia coli capazes de inibir a própria fagocitose em sepse}

Tese apresentada à Faculdade de Medicina da Universidade de São Paulo para obtenção do título de Doutor em Ciências

Programa de Ciências Médicas

Área de Concentração: Processos Imunes e Infecciosos

Orientador: Dr. Fabiano Pinheiro da Silva

Coorientador: Dr. Ricardo José Giordano

São Paulo

2015 
Dados Internacionais de Catalogação na Publicação (CIP)

Preparada pela Biblioteca da

Faculdade de Medicina da Universidade de São Paulo

Creprodução autorizada pelo autor

\section{Beppler, Jaqueline}

Identificação de peptídeos de Escherichia coli capazes de inibir a própria fagocitose em sepse / Jaqueline Beppler. -- São Paulo, 2015.

Tese(doutorado)--Faculdade de Medicina da Universidade de São Paulo.

Programa de Ciências Médicas. Área de concentração: Processos Imunes e Infecciosos.

Orientador: Fabiano Pinheiro da Silva.

Coorientador: Ricardo José Giordano.

Descritores: 1.Sepse 2.Receptores de IgG 3.Inflamação 4.Proteína WZxE 5.Fagocitose 6.Escherichia coli 7.Biblioteca de peptídeos 8.Receptores Fc 9.Imunoglobulina G 10.Síndrome de resposta inflamatória sistêmica 
Esta tese está de acordo com as seguintes normas, em vigor no momento desta publicação:

Referências: adaptado de International Committee of Medical Journals Editors (Vancouver).

Guia de apresentação e dissertações, teses e monografias.

Elaborado por Anneliese Cordeiro da Cunha, Maria Julia de A.L. Freddi, Maria F. Crestana, Marinalva de Souza Aragão, Suely Campos Cardoso, Valéria Vilhena. 3플. Edão Paulo: Divisão de Biblioteca e Documentações; 2012

Abreviaturas dos títulos dos periódicos de acordo com List Journals Indexed in Index Medicus. 



\section{Agradecimentos}

Ao Dr. Fabiano Pinheiro da Silva e Dr. Ricardo José Giordano, pela orientação, apoio e confiança, que foram primordiais para a realização dessa tese.

Aos meus pais e irmã. E ao Fábio, por toda força, compreensão e carinho.

Aos colegas do IQ/USP, e INSERM U699/Paris VII em especial a Jussara e a Ara que me acolheram e foram fundamentais para o desenvolvimento deste projeto.

Ao Paulo Sérgio, por toda contribuição, que foi essencial para o desenvolvimento do projeto .

Ao Dr. Renato Costa Monteiro pela contribuição na realização dos experimentos, bem como pela orientação e por me proporcionar um excelente estágio em Paris.

À FAPESP e à CAPES pelo suporte financeiro. 

"Ninguém poderá jamais aperfeiçoar-se, se não tiver o mundo como mestre." 




\section{Sumário}

Lista de Abreviaturas, Símbolos e Siglas

Lista de Figuras e Tabelas

Resumo

Abstract

1. Introdução

1.1 - Sepse: Clínica e Epidemiologia.......................................................... 31

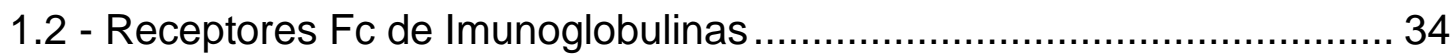

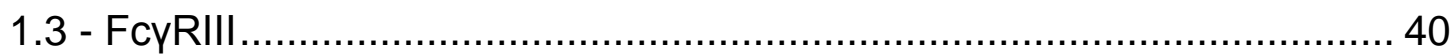

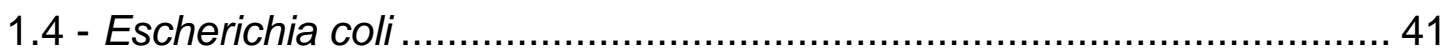

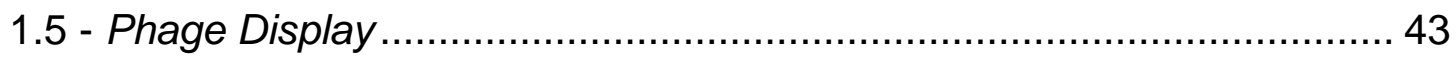

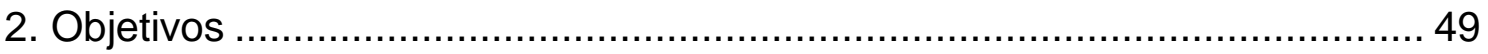

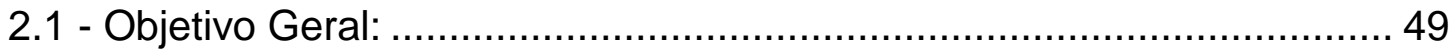

2.2 - Objetivos Específicos:.................................................................. 49

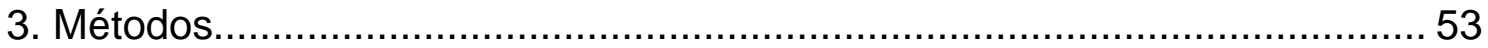

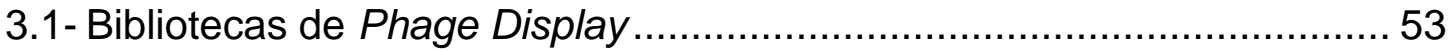

3.2 - Produção, purificação e titulação dos fagos ………………………...... 53

3.3 - Ensaios de biopanning contra os alvos ................................................. 54

3.4 - Seleção de clones, PCR e sequenciamento para a determinação do

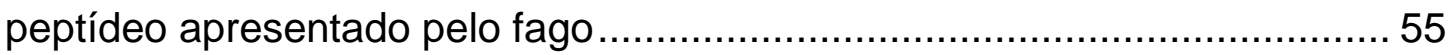

3.5 - Caracterização dos peptídeos identificados e seus receptores.............. 56

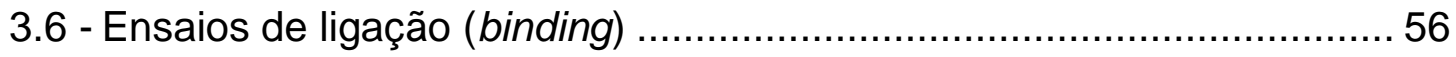

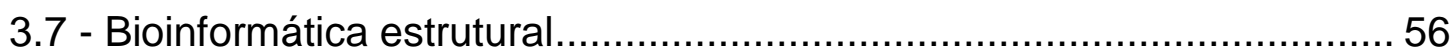

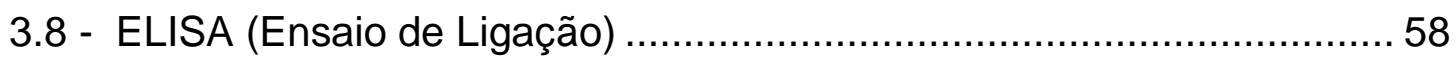

3.9 - Validação dos pares peptídeos e proteínas ligantes do CD16 ............... 59

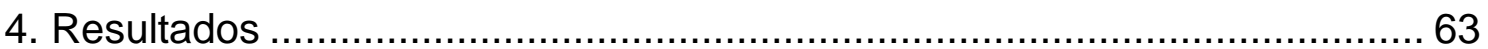


4.1 - Panning in vitro para identificação de alvos moleculares contra o

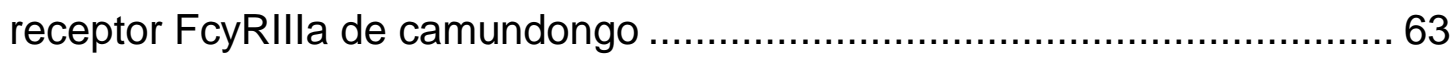

4.2 - Sequenciamento e análise por Bioinformática ................................. 64

4.3 - Phage display - Ensaio de Ligação (Binding) ................................... 68

4.4 - Análise avançada por bioinformática.............................................. 70

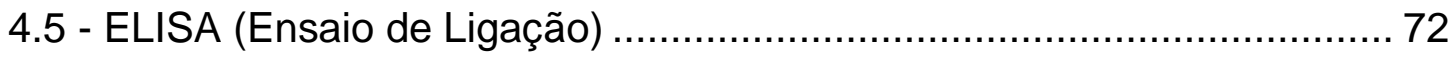

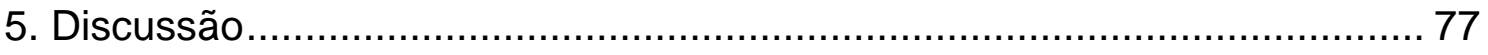

5.1 - Identificação de peptídeos e proteína .......................................... 81

5.2 - LPS, antígeno O e proteínas Wzx ............................................. 84

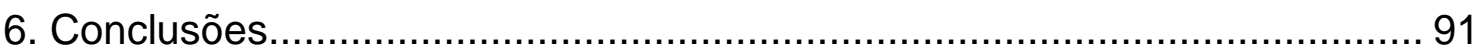

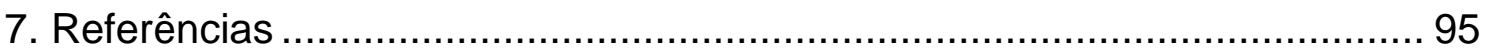




\section{Lista de Abreviaturas, Símbolos e Siglas}

Aa Aminoácidos

Ac Anticorpos

ADCC do inglês "antibody-dependent mediated citotoxicity " traduzido por Citotoxicidade Celular Dependente de Anticorpo

Ag Antígenos

BASES Estudo Epidemiológico Brasileiro de Sepse

BSA do inglês "Bovine Serum Albumin" traduzido por Albumina sérica bovina

$\mathrm{Ca}^{2+} \quad$ íon Cálcio

CLP Ligação cecal e punção

CTL do inglês "Cytotoxic T lymphocyte" traduzido por Linfócitos T Citotóxicos

DAEC E.coli de aderência difusa

DNA em português ADN: ácido desoxirribonucleico

E. coli Escherichia coli

EaggEC E. coli enteroagregativa

EC domínios extracelulares

EHEC E. coli enterohemorrágica

EIEC E. coli enteroinvasora

EPEC E.coli enteropatogência

ETEC E. coli enterotoxigênica

EUA Estados Unidos da América 
Fagos Bacteriófagos

Fc $\mu R \quad$ Receptores de IgM

FcaRI Receptor I de IgA ou CD89

FcR Receptor Fc de Imunoglobulina

$\mathrm{FcR} \gamma \quad$ Receptor Fc associado a cadeia gamma

FcRa Receptor Fc associado a cadeia alfa

FcR $\beta \quad$ Receptor Fc associado a cadeia beta

FcaR Receptores de IgA

FcyR Receptores de IgG

FcyRI Receptores I de IgG ou CD64

FcyRII Receptores II de IgG ou CD32

FcyRIII Receptores III de IgG ou CD16

FcyRIV Receptores IV de IgG

$\mathrm{Fc}^{\bar{\delta} \mathrm{R}} \quad$ Receptores de $\lg \mathrm{D}$

FceR Receptores de lgE

IC domínios intracitoplasmáticos

IFN-Y Interferon gama

IgA Imunoglobulina A

$\lg \mathrm{D}$ Imunoglobulina D

IgE Imunoglobulina E

IgG Imunoglobulina $G$

IgM Imunoglobulina M

IL Interleucina

ITAM motivos de ativação de imunoreceptor baseados em tirosina 
ITAMi motivos de ativação de imunoreceptor baseados em tirosina inibidor

ITIM motivos de inibição de imunoreceptor baseados em tirosina

LB Luria-Bertani

LEE do inglês "locus of enterocyte effacement"

LPS Lipopolissacarídeo

MG Miligrama

$\mathrm{mL} \quad$ Mililitro

mM Milimolar

$\mathrm{mm}^{3} \quad$ Milímetros cúbicos

$\mathrm{NaCl} \quad$ Cloreto de Sódio

NK do inglês "Natural Killer"

nM Nanômetros

NMEC E.coli causadora da meningite neonatal

PAl do inglês "pathogenicity islands" traduzido por ilhas de patogenicidade

PAMP do inglês "Pathogen-associated molecular patterns " traduzido por Reconhecimento de padrões associados ao patógeno

PBS do inglês " Phosphate Buffered Saline" traduzido por Tampão fosfato-salino

PCR do inglês " Polymerase Chain Reaction" traduzido por Reação em Cadeia da Polimerase

PEG Polietilenoglicol

PIRO P: predisposição I: infecção R:resposta O: disfunção orgânica PKC proteína-quinase $\mathrm{C}$ 
PRR do inglês "Pattern recognition receptors " traduzido por Receptores de reconhecimento padrões

RBL do ingles "rat basophilic leukemia"

RNA do inglês “Ribonucleic acid" traduzido por Ácido ribonucleico

SDMO Síndrome da disfunção (ou insuficiência) de múltiplos órgãos

SIRS do inglês "Systemic Inflammatory Response Syndrome" traduzido por Síndrome da resposta inflamatória sistêmica

ssDNA DNA de fita simples

SSTT Sistema de secreção tipo III

STEC E.coli produtora de toxina tipo Shiga

TM domínios transmembrana

TNF do inglês "Tumor Necrosis Factor" traduzido por Fator de necrose tumoral

TUs $\quad$ unidades transdutoras de bactéria

UPEC E. coli uropatogência

UTI Unidade de Terapia Intensiva

VBB do inglês "Vegetal Blocking Buffer"

$\beta$-hex $\beta$-hexosaminidase

$\mu$ Micrograma

$\mu \mathrm{L} \quad$ Microlitro 


\section{LISTA DE FIGURAS}

E TABELAS 



\section{Lista de Figuras}

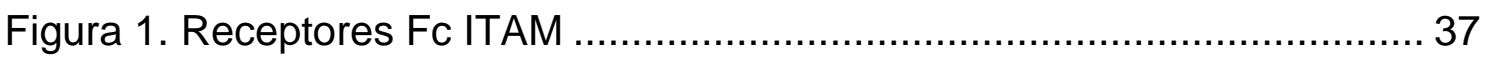

Figura 2. Receptores para Imunoglobulina G..................................... 41

Figura 3. Fotografia eletrônica de Escherichia coli................................... 42

Figura 4. Partícula viral (bacteriófago). ............................................... 44

Figura 5. Biopanning. Esquema ilustrativo do ciclo de seleção de fagos. ........ 55

Figura 6. Phage display in vitro contra o receptor FcyRIlla de camundongo ........6 64

Figura 7. Análise do sequenciamento por Bioinformática. ............................6 67

Figura 8. Análise no software blastp do peptídeo CFGAHGVFFC.................68 68

Figura 9. Análise no software blastp do peptídeo CYWGGTEGAC. ...............68

Figura 10. Ensaio de ligação dos fagos selecionados para validação frente aos receptores alvos (FcyRIIIA camundongo e FcyRIIIA humano)................. 70

Figura 11. Ensaio de ligação (binding) dos peptídeos sintéticos - ELISA........ 72 Figura 12. Ensaio de ligação (binding com receptor humano) da E.coli K12 wild type e mutada - ELISA .................................................................... 73

Figura 13. Ensaio de ligação (binding com receptor humano) da E.coli K12 wild type e mutada - ELISA ............................................................ 73

\section{Lista de Tabelas}

Tabela 1. Definição da conferência internacional sobre Sepse ....................... 33

Tabela 2. Peptídeos identificados após sequenciamento do DNA codificante . 65

Tabela 3. Peptídeos alinhados usando o software ClustalW ..........................66

Tabela 4. Hits oriundos da análise por bioinformática ............................... 71 

RESUMO 

Resumo

Beppler, J. Identificação de peptídeos de Escherichia coli capazes de inibir a própria fagocitose em sepse. [tese] São Paulo: Faculdade de Medicina, Universidade de São Paulo; 2015.

Introdução: Sepse é uma síndrome complexa definida por resposta inflamatória sistêmica, de origem infecciosa e caracterizada por manifestações múltiplas que podem determinar disfunção ou falência de um ou mais órgãos ou sistemas. É a principal causa de morte em unidades de terapia intensiva em pacientes críticos e tem representado uma fonte constante de preocupação para os sistemas de saúde em todo o mundo, devido, principalmente, às taxas elevadas de morbimortalidade. O tratamento da sepse é um desafio e continua a ser uma tarefa difícil devido a inúmeros fatores interferentes. Um estudo do nosso grupo demonstrou que a Escherichia coli (E. coli) é capaz de se ligar CD16 de um modo independente de opsonina, levando a um aumento na resposta inflamatória e a inibição da sua própria fagocitose, por conseguinte, procurou-se identificar os peptídeos no proteoma da $E$. coli envolvidos neste cenário.

Metodologia: Utilizando a metodologia de Phage Display, que consiste numa técnica de clonagem, que permite a expressão de diversas sequências de peptídeos na superfície de bacteriófagos, nós identificamos 2 peptídeos que obtiveram interação com CD16. Após a seleção dos peptídeos identificamos uma proteína de membrana de E.coli que possui alta similaridade com um de nossos peptídeos selecionados. Nós acreditamos que esta proteína de membrana possa estar envolvida no processo de evasão imune desenvolvida pela E.coli e parece ser um forte candidato como uma nova opção terapêutica para controlar infecções por E. coli.

Conclusão: A identificação de proteínas capazes de induzir inibição de fagocitose, através do receptor CD16, pode ser usada como uma nova forma de tratamento da sepse, assim como explorada no tratamento de doenças autoimunes.

Descritores: Sepse; Receptores de IgG; Inflamação; WzxE; Fagocitose; Escherichia coli; Biblioteca de Peptídeos; Receptores Fc; Imunoglobulina G; Síndrome da Resposta Inflamatória Sistêmica. 

ABSTRACT 



\begin{abstract}
Beppler, J. Identification of Escherichia coli peptides that can inhibit its own phagocytosis in sepsis. [thesis] São Paulo: "Faculdade de Medicina, Universidade de São Paulo"; 2015.
\end{abstract}

Introduction: Sepsis is a complex syndrome defined by a systemic inflammatory response of infectious origin and characterized by multiple manifestations that can determine dysfunction/failure of one or more organs and systems. It is the leading cause of death in intensive care units and represents a major health problem around the world, mainly due to its high mortality and morbidity rates. The treatment of sepsis is challenging and remains a difficult task due to numerous interfering factors. A study from our group demonstrated that Escherichia coli $(E$. coli) is able to bind CD16 in an opsoninindependent manner, leading to an increase in the inflammatory response and inhibition of its own phagocytosis, therefore we sought to identify the peptides in the $E$. coli proteome involved in this scenario. Methods and Results: Using the Phage Display technique, which is a cloning technique that allows the expression of various peptide sequences on the surface of bacteriophages (phages) and selecting these on the basis of affinity for a target molecule, we identified two peptides that interact with CD16. Next, using bioinformatic tools, we found an $E$. coli membrane protein that has high similarity with one of our selected peptides. We believe this membrane protein is involved in the process of immune evasion developed by $E$. coli and it is a strong candidate as a new therapeutic option to control $E$. coli infections. Conclusion: The identification of proteins capable of inducing inhibition of phagocytosis through the CD16 receptor, can be used as a new treatment of sepsis, as well as exploited in the treatment of autoimmune diseases.

Descriptors: Sepsis; IgG receptors; Inflammation; WzxE protein; phagocytosis; Escherichia coli; Peptide Library; Fc receptors; Immunoglobulin G; Systemic Inflammatory Response Syndrome. 



\section{INTRODUÇÃO}





\section{Introdução}

\section{1- Sepse: Clínica e Epidemiologia}

Sepse é uma síndrome clínica complexa definida por resposta inflamatória sistêmica (SIRS), de origem infecciosa e caracterizada por manifestações múltiplas que podem determinar disfunção ou falência de um ou mais órgãos ou sistemas, apresentando uma alta mortalidade. Está associada a uma desregulação da resposta inflamatória normal, com liberação maciça e descontrolada de mediadores inflamatórios, criando uma cadeia de eventos que levam à lesão tecidual (1-4). Cerca de $70 \%$ dos pacientes admitidos em unidades de terapia intensiva (UTI) desenvolvem SIRS, podendo também ocorrer em associação a eventos não infecciosos, como traumatismos múltiplos, cirurgias, pancreatite e queimaduras. Em cerca de 10 a $25 \%$ dos pacientes críticos, esta síndrome já está presente no momento da admissão na UTI (4-7).

Sepse é a principal causa de morte em unidades de terapia intensiva (UTI) e uma das principais causas de óbito nos EUA (8). Em torno de $2 \%$ a $11 \%$ das internações hospitalares e em UTI são por conta desta doença (9). A mortalidade varia na maioria dos estudos entre $20 \%$ e $80 \%$, dependendo do grupo em estudo (10).

Um estudo epidemiológico nos EUA demonstrou que nos últimos 20 anos, a incidência da sepse aumentou de 82,7 para $240,4 / 100$ mil habitantes, bem como as mortes relacionadas a ela, ainda que a taxa de mortalidade geral entre os pacientes com sepse tenha sido reduzida nesse período (3). Em outro estudo, os custos causados pela sepse foram maiores em lactentes, nos não sobreviventes, nos pacientes de UTI, nos pacientes cirúrgicos e naqueles com 
falência de mais de um órgão (11).

Superando as doenças cardiovasculares, sepse, SIRS e choque séptico, juntos, representam a causa mais importante de morte em UTI de adultos (12).

Dados do estudo BASES revelam que no Brasil a sepse é a principal geradora de custos nos setores público e privado. Em 2003 os gastos com pacientes de UTI somaram $\mathrm{R} \$ 17,34$ bilhões, o que representa aproximadamente $30 \%$ dos gastos totais com a área de saúde (13).

Apesar dos avanços em relação ao tratamento, incluindo administração de antibióticos, e medidas de suporte à vida (ventilação mecânica, hemodiálise, uso de drogas vasoativas, dentre outras) ainda buscamos uma melhor compreensão da doença (14). Pois apesar do desenvolvimento de novos antibióticos e aprimoramento de medidas de tratamento intensivo, nas últimas décadas a mortalidade não tem se modificado $(5,7,15,16)$.

Intensos estudos estão sendo realizados nas áreas de Biologia Celular, Imunologia, Microbiologia e Genética para uma maior elucidação e compreensão da fisiopatologia desta doença, incluindo a investigação de biomarcadores que permitam um diagnóstico rápido e eficaz, assim como a monitorização da evolução, prognóstico e resposta ao tratamento. Dentre eles, incluem-se aspectos de individualização da abordagem do paciente e interferência direta em mecanismos celulares (3,8-11,17-21).

Desde o Consenso de 1991, as novas definições e os critérios para o diagnóstico de sepse, permitiram que os pesquisadores falassem a mesma linguagem e comparassem os resultados de seus estudos. Em 2001, a Conferência Internacional de Definição da Sepse, optou por não modificar as definições vigentes e por ampliar a lista de sinais e sintomas desta doença 
(10).

Sepse é uma doença definida por critérios clínicos, podendo manifestarse por uma variedade de situações, dentre elas (Tabela 1): $(10,1721)$

Tabela 1. Definição da Conferência Internacional sobre SEPSE

\begin{tabular}{l}
\hline SIRS Presença de 2 ou mais dos seguintes critérios: \\
1. bradicardia ou taquicardia \\
2. bradpnéia ou taquipnéia \\
3. febre ou hipotermia \\
4. \\
\end{tabular}
SEPSE SIRS na presença de agente infecioso
SEPSE Sepse associada à: disfunção orgânica, hipoperfusão (acidose lática, GRAVE oligúria, alteração do estado de consciência) ou hipotensão responsiva a volume.

CHOQUE Sepse não responsiva a volume, havendo a necessidade do uso de drogas vasoativas para manutenção de pressão arterial média adequada.

SDMO Presença de falência de três ou mais órgãos em paciente crítico, no qual a homeostasia não pode ser mantida sem intervenção.

SIRS: síndrome da resposta inflamatória sistêmica. SDMO: síndrome da disfunção (ou insuficiência) de múltiplos órgãos. Adaptado de ACCP/SCCM (10).

Os limites que separam a sepse da sepse grave, entretanto, não são facilmente identificados na prática clínica $(18,19)$. Portanto, a última conferência sobre sepse propôs o desenvolvimento de um sistema de estagiamento para esta doença, caracterizando a síndrome com base nos fatores predisponentes e nas condições pré-mórbidas, na natureza da infecção subjacente, nas características da resposta do hospedeiro e na extensão da disfunção de órgãos resultante (sistema PIRO) (10).

Outro aspecto relevante a ser considerado é o da sepse secundária em pacientes críticos internados por diferentes causas, seja pelo seu comprometimento imunológico, seja pelas condutas e procedimentos médicos 
imputados aos mesmos, durante sua permanência nas UTIs e hospitais (18).

A interação do hospedeiro com bactérias é um fenômeno comum, entretanto a ocorrência de infecção e complicações sistêmicas, não é a regra. Acredita-se que este fenômeno acontece, porque existe um equilíbrio entre os fatores de defesa do hospedeiro e os fatores de virulência dos agentes infecciosos. O desequilíbrio entre estes, comum no ambiente hospitalar, em razão das doenças de base, de terapia intensiva e do uso de antimicrobianos, pode propiciar o surgimento de um processo infeccioso (4).

Os mecanismos adaptativos da resposta do hospedeiro na sepse são de natureza complexa, e as respostas imunes e inflamatórias medeiam as alterações funcionais fornecendo a base fisiopatológica para as manifestações clínicas da doença (4).

Importantes progressos em relação à compreensão da fisiopatologia da sepse vêm sendo realizados, destacando-se o mecanismo de reconhecimento de antígenos bacterianos e uma compreensão melhor das vias de sinalização celular, apesar de que ainda estamos muito distantes de uma boa compreensão da doença (4).

\section{2- Receptores Fc de Imunoglobulinas}

O funcionamento efetivo do sistema imune depende da interação entre imunidade inata e adaptativa. As ramificações do sistema imune (celular e humoral) assumem diferentes papéis na proteção do hospedeiro. Os executores humorais são os anticorpos (Ac), que podem se ligar e neutralizar os antígenos (Ag). A proteção primária mediada por anticorpos se encontra do 
lado externo das células. Já a imunidade celular tem como papel fundamental a detecção e eliminação de células que contém patógenos intracelulares e também e também aquelas células que sofreram modificações genéticas como células tumorais (22).

Tanto as células específicas, quanto as não específicas a antígenos podem contribuir para a resposta imune celular. Células antígeno-específicas incluem linfócitos T citotóxicos CD8+ (CTL) e células Th CD4+ secretoras de citocinas que medeiam a hipersensibilidade tardia. Células não específicas incluem as células NK e tipos celulares não linfóides, como macrófagos, neutrófilos e eosinófilos.

Respostas imunes mediadas por células podem ser divididas em dois grupos. Um deles compreende células efetoras que tem atividade citotóxica direta, eliminando células estranhas e alteradas, incluindo aquelas infectadas por vírus e células tumorais, como: CTLs antígeno-específicos e células não específicas, como NK e macrófagos, e o outro grupo incluem as células TH. As respostas mediadas por linfócitos citotóxicos são baseadas na morte celular perforina-dependente, FasL dependente ou pela combinação dos dois sistemas (22).

Para que haja resposta à presença de antígenos, as células B e T codificam suas imunoglobulinas e os receptores de células $T$, respectivamente, para gerar diversos receptores de antígenos. Durante a resposta imune, os linfócitos B se diferenciam em plasmócitos produtores de anticorpos. A interação antígeno-anticorpo é reconhecida na superfície celular por uma classe de glicoproteínas de membrana chamadas receptores Fc de imunoglobulinas (FcR) (4). 
A atividade de cada anticorpo depende diretamente da interação de suas porções Fc com sistemas efetores, entre eles células e sistema complemento (23). A interação entre Ac e FcR, resulta em diversas respostas celulares, como apresentação de antígeno, citotoxicidade celular dependente de anticorpo (ADCC), degranulação, fagocitose, endocitose e desencadeamento de cascatas de sinalização celular, que liberam citocinas e mediadores inflamatórios (24).

Os receptores Fc foram descritos primordialmente como um grupo heterogêneo de glicoproteínas de superfície de células hematopoiéticas que auxiliam na interação do imunocomplexo formado com células efetoras do sistema imune, e, mais tarde, foram identificados formas solúveis destas moléculas em fluídos biológicos (25).

São descritos atualmente receptores $F c$ de $\lg G, \lg A, \lg E, \lg D$ e $\lg M$, e através da sua especificidade por isótopos de imunoglobulinas (lg) são denominados como FcyR para receptores de $\lg G$, FceR para IgE, FcaR para $\lg A, F^{\delta} \mathrm{R}$ para $\lg \mathrm{D}$ e $\mathrm{Fc} \mu \mathrm{R}$ para $\lg \mathrm{M}$ (23-28).

Conhecemos atualmente quatro grupos de receptores de IgG (FcyRs): FcyRI também denominado como CD64, FcyRII (CD32) e FcyRIII (CD16),e FcyRIV presentes em humanos. A diferenciação dos receptores FcyRs se dá de acordo com a homologia estrutural, afinidade, especificidade às subclasses de lgG, expressão nas células e funções biológicas $(29,30)$.

Os receptores FcyRs podem ser divididos de acordo com a afinidade para IgG; onde FcyRI (CD64) é um receptor de alta afinidade, FcyRIII (CD16) e FcyRIV de média afinidade, e FcyRII (CD32) de baixa afinidade. Além disso, podem ser subdivididos de acordo com sua estrutura, podendo apresentar dois 
ou três domínios extracelulares (EC), domínios transmembrana (TM) e domínios intracitoplasmáticos (IC) (31).

Ademais, existe outra classificação para os receptores Fc, baseada na sua capacidade de estimular ou inibir funções como fagocitose, citotoxicidade, degranulação, apresentação de antígenos e produção de citocinas via motivos de ativação ou inibição de imunoreceptor baseados em tirosina, abreviados como ITAM (Figura1) ou ITIM respectivamente (29).
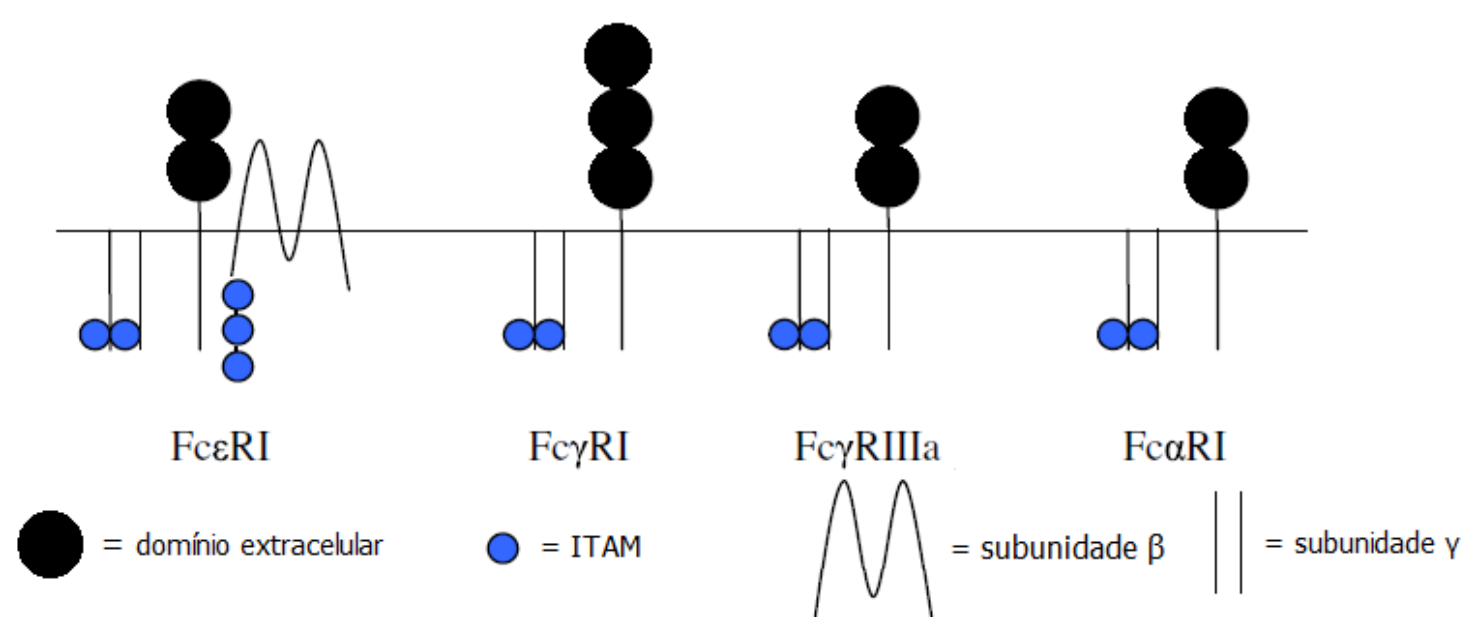

Figura 1. Receptores Fc ITAM. Adaptado de: Silva, 2005 (35); Gilfillan and Thaczyk, 2006 (40); e Rivera and Gilfillan, 2006 (41).

Tanto receptores ativadores (ITAM), como receptores inibidores (ITIM) podem ser encontrados co-expressos, com frequência, na membrana de alguns tipos celulares. Como ambas as classes de receptores apresentam afinidade e especificidade comparáveis, agregação entre elas é comum, assim como entre componentes da mesma classe, modulando, a magnitude das respostas efetoras. FcદRI, FcyRIIB e FcyRIIIA são co-expressos em mastócitos e células de Langerhans; FcүRI, FcyRIIB e FcyRIIIA em macrófagos murinos e FcyRI, FcyRIIB e FcyRIIIB em neutrófilos humanos (26, 32).

Os FcR podem ser agregados por Ac ou Ag multivalentes. A ativação 
celular não é deflagrada se o FcR não possui nem ITAM nem ITIM. Alguns FcR sem ITAM na região citoplásmica, utilizam uma outra molécula que contém um motivo ITAM chamada cadeia FcR gamma ( $\mathrm{FcR} \gamma)$ para transdução de sinal (26). ITAM é caracterizado por uma seqüência $Y x x L$ repetida duas vezes e separadas por sete aminoácidos variáveis. FcRs com ITAMs são de dois tipos: 1) receptores com múltiplas cadeias, compostos de uma subunidade alfa, onde - ligante se conecta a outras subunidades, as quais são responsáveis por transdução do sinal; 2) o ITAM é único e as seqüências YxxL são separadas por 12 aminoácidos, ao invés de 7; os receptores são de cadeia única e exclusivos em humanos (FcyRIIA e FcyRIIC).

Quatro são os receptores com ITAM: FcyRI, FcyRIIIA, FceRI e FcaRI. Todos se associam com a cadeia gamma dos FcR (FcRY), com exceção do FceRl, que se associa à subunidade $\beta$ (FcR $\beta)$, por intermédio da subunidade FcRa. Existe um ITAM no domínio IC de cada cadeia gamma, assim como um ITAM no domínio carboxi-terminal do FcRß, permitindo sinalização intracelular desses receptores. A subunidade $\beta$, associada ao FcعRI, contém um ITAM, mas não é capaz de deflagrar sinalização intracelular isoladamente. Lin et al. demonstraram que tal cadeia funciona como um amplificador de sinal, através de mensuração da ativação de syk e mobilização de cálcio (33). A cadeia gamma se associa aos FcRs, na forma de homodímeros (YY) e é necessária para a expressão do FcعRI, do FcyRI e do FcyRIIIA, na superfície celular; além disso, aumenta a afinidade tanto do FcyRl, quanto do FcyRIIIA ao ligante, supostamente por alteração da estrutura quaternária do receptor (34).

Após a agregação dos FcR com ITAM, a fosforilação dos receptores, desencadeia a ativação de diversas proteínas tirosina-quinases. Src quinases 
é o primeiro grupo a ser ativado, seguido das syk quinases. Estas tirosinaquinases, fosforilam diversos substratos intracelulares, entre eles, fosfolipídioquinases, fosfolipases, moléculas adaptadoras e proteínas do citoesqueleto; já a fosforilação de tirosinas induzida pelo FcR, é mediada por fosfatases de membrana e citoplasmáticas que ativam diversas vias, resultando em: 1) influxo celular de cálcio; 2) ativação da proteína-quinase C (PKC); 3) transcrição de diversos genes. Assim, a elevação do cálcio intracelular (pico sustentado) abre os canais de cálcio da membrana plasmática, caracterizando a ativação celular induzida por todos os FcRs com ITAMs (35).

Diversos receptores ITAMs ativam as mesmas respostas, quando expressos nas mesmas células. Ao contrário, quando expressos em células diversas, o mesmo receptor efetua respostas diferentes, sugerindo que as respostas parecem depender mais do tipo celular do que do próprio receptor. A associação de FcRs com ITAMs induz respostas resultante da ativação celular e de fenômenos de internalização do ligante, mediando endocitose, assim como fagocitose (35).

Recentemente, o conceito ITAM/ITIM como módulos de ativação/inibição foi questionado pela equipe francesa associada a este projeto. Pasquier et al (36) foram pioneiros em mostrar que monômeros de $\lg A$ induziam sinais inibidores através do motivo ITAM do receptor CD89 (FcaRI). O sinal característico do ITAM inibidor (denominado ITAMi) é o recrutamento transiente da quinase Syk seguida pelo recrutamento estável de uma tirosina fosfatase, SHP-1 resultando em inibição de múltiplos receptores heterologos através da formação de estruturas chamadas "inibissomes" (37). Por outro lado, a ligação de polímeros de IgA ou complexos induzem um recrutamento estável de syk 
sem SHP-1 que conduz a uma ativação celular (36).

Estudos do nosso grupo em colaboração com a equipe francesa mostraram que de modo inesperado, E. coli se liga diretamente com receptores FcyRIII de camundongos na ausência de anticorpos. Este receptor em camundongos, esta associado à cadeia FcR $\gamma$ que contém um ITAM e funciona como receptor ativador após interação com complexos de lgG-Ag. Porém, a interação entre E. coli e FcyRIII induz um sinal ITAMi com recrutamento estável de SHP-1 e inibição de fagocitose e indução de TNF $\alpha$ (molécula pró sepse). As bactérias $E$. coli mimetizam as IgG monoméricas, ligantes naturais do Fc $\gamma R$ III capazes de induzir o ITAMi. Estudos experimentais em animais deficientes em FçRIII confirmaram esta hipótese mostrando uma proteção significativa contra a sepse e diminuição da mortalidade após peritonite induzida pela ligação cecal e punção (CLP). Estes resultados sugerem que o FcyRIIIA poderia ser um alvo das E. coli $(38,39)$.

\section{3- Fc $\gamma R$ III}

Também conhecido como CD16 (Figura 2), é uma proteína glicosilada com peso molecular variando entre 50 a $80 \mathrm{kDa}$. Este receptor liga IgG na forma de IC, com especificidade para lgG1 e lgG3 e mínima ligação para IgG4 e IgG2. Em humanos, encontramos dois homólogos: FcyRIIIA presente em macrófagos e células Natural Killer, e FcyRIIIB presente em neutrófilos. FcyRIIIA também está presente em camundongos $(31,42,43)$. Nas células NK, - FcyRllla medeia a morte de células alvos, revestidas por lgG, pelo mecanismo de ADCC. Além disso, este receptor estimula a produção de 
superóxido, e atua na fagocitose, endocitose, apoptose e liberação de citocinas como IFN-y e TNF- $\alpha$ (31).

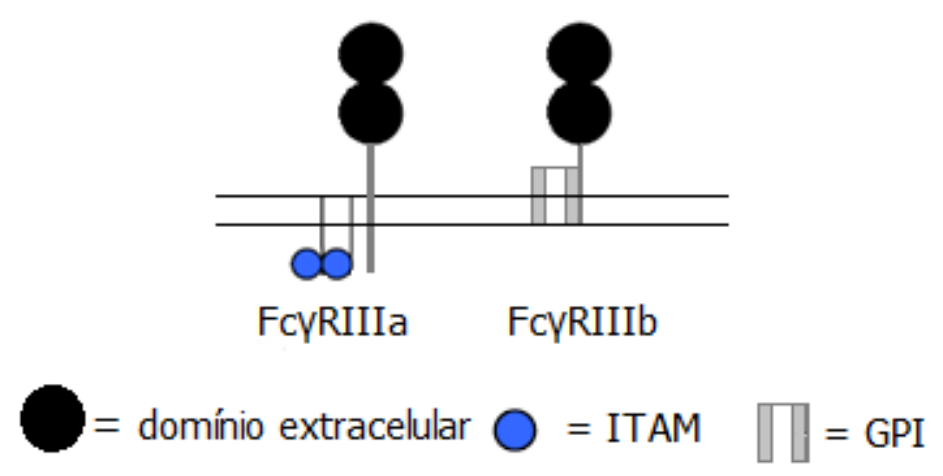

Figura 2. Receptores para Imunoglobulina G: CD16a (FcyRIIla) e CD16b (FcyRIIIb). Adaptado de Gillis 2014 (44). ITAM = motivo de ativação de imunoreceptor baseado em tirosina. GPI = glicosil-fosfatidil-inositol.

\section{4- Escherichia Coli}

Escherichia Coli (Figura 3) é um bacilo Gram negativo pertencente à família Enterobacteriacea. Caracteriza-se por apresentar metabolismo anaeróbio facultativo, e por colonizar o trato gastrointestinal de humanos, sendo, portanto, constituinte da sua microbiota. Porém dentre as E.coli, existem diversas cepas potencialmente patogênicas; fato devido à presença de genes de virulência, que codificam proteínas, possibilitando a colonização, penetração e invasão de novos sítios em seus hospedeiros, originando infecções, principalmente no trato gastrointestinal, urinário, e, por vezes dando origem à sepse $(45-47)$.

A expressão de adesinas, hemolisinas, aerobactina; presença de cápsula, produção de citotoxinas e enterotoxinas; e a capacidade de invadir tecidos e resistir aos fatores séricos inibitórios do hospedeiro caracterizam alguns dos fatores de virulência presentes nas E.coli. A presença destes 
fatores, fazem com que os mecanismos de defesa do hospedeiro sejam ineficazes, desencadeando os processos infecciosos (48).

As cepas da E.coli são classificadas por meio dos sorotipos determinados pelos antígenos somático $(\mathrm{O})$, capsular $(\mathrm{K})$, flagelar $(\mathrm{H})$ e pela presença de pili $(F)$. Além disso, a $E$. coli recebeu a classificação por meio de seus patótipos: EPEC (E.coli enteropatogência), EHEC (E. coli enterohemorrágica), DAEC (E.coli de aderência difusa), ETEC (E. coli enterotoxigênica), EIEC (E. coli enteroinvasora), STEC (E.coli produtora de toxina tipo Shiga), UPEC (E. coli uropatogência), EaggEC (E. coli enteroagregativa), NMEC (E.coli causadora da meningite neonatal) etc (48$50)$.

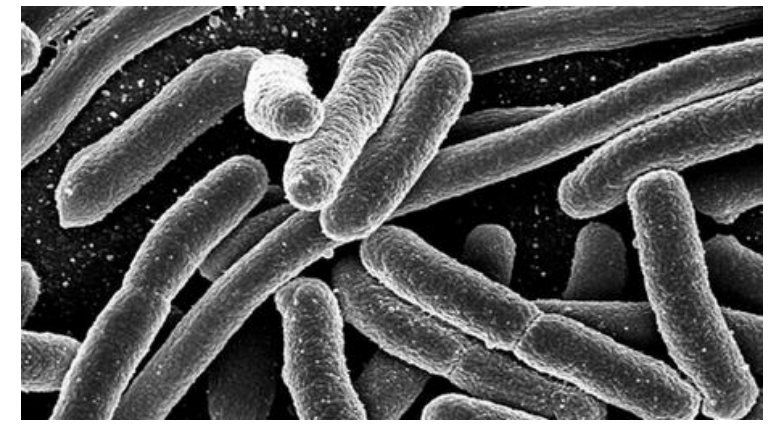

Figura 3. Fotografia eletrônica de Escherichia coli (51)

Bactérias Gram negativas em especial Escherichia coli representam a maior causa de infecção em humanos e consequentemente estão entre os principais agentes causadores de sepse. 


\section{5- Phage Display}

Descrita inicialmente por SMITH (1985) (52), o termo define uma técnica de clonagem, que permite a expressão de diversas sequências de peptídeos na superfície de bacteriófagos (fagos), e a seleção destas, com base na afinidade por uma molécula-alvo (53). Esta técnica de seleção onde uma biblioteca de peptídeos ou proteínas é expressa na superfície dos fagos com o material genético codificante para cada peptídeo localizado no genoma viral é denominada Phage Display (54). É uma técnica, que permite ensaios de seleção de peptídeos contra diferentes alvos em diferentes situações, como por exemplo, ensaios de seleção de peptídeos (chamados panning ou biopanning) podem ser realizados in vitro contra: moléculas alvo aderidas em superfície; células que podem ou não ser estimuladas para alterar a expressão de receptores; tecidos dissecados; e também in vivo injetando os fagos na circulação do animal, retirando os órgãos de interesse e selecionando aqueles fagos que expressam peptídeos que interagem com a vasculatura de diferentes órgãos do organismo $(52,55)$.

Esta técnica baseia-se na construção de bibliotecas de bacteriófagos filamentosos, onde pequenos peptídeos (entre 5 e 15 aminoácidos) são apresentados numa das proteínas do capsídeo viral (52) .

Bacteriófagos são partículas virais pertencentes à família Inoviridae que infectam algumas bactérias gram-negativas usando o pilus sexual como receptor. As partículas destes fagos, (linhagens $\mathrm{M} 13$, f1 e fd), que infectam via pilus $\mathrm{F}$ a Escherichia coli são formadas por DNA de fita simples (ssDNA) envoltos por uma cápsula protéica, composto pelas proteínas plll, pVI, pVII, 
pVIII, plX (Figura 4 ), e são estes os fagos filamentosos do gênero Inovirus que são preferencialmente empregados no Phage Display, isto porque esses fagos não causam infecção lítica na célula da $E$. coli, mas induzem um estado onde ela produz e secreta continuamente partículas virais sem sofrer lise, possibilitando assim a obtenção de um grande número de fagos (56-59).

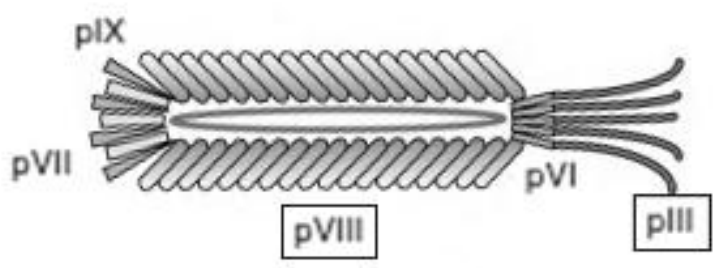

Figura 4. Partícula viral apresentando as proteínas utilizadas para expressão dos peptídeos exógenos (60). Destaque para pllI e pVIII, preferencialmente utilizadas em Phage display.

Das cinco proteínas do fago, as mais utilizadas para apresentar peptídeos são a pllI e pVIII. A pllI apresenta 5 cópias por vírion, é sintetizada com um sinal no peptídeo N-terminal (clivado na translocação na membrana interna); a porção C-terminal se encontra no citosol, e a N-terminal se encontra no periplasma e permite a inserção de longos fragmentos. Já a pVIII apresenta 2700 cópias por vírion e é sintetizada como um precursor fundamental para a inserção da mesma na membrana citoplasmática da célula bacteriana hospedeira. Quando madura possui 50 aa, sendo que até 6 aa podem ser inseridos nela sem seu rompimento $(61,62)$.

Uma biblioteca é um pool de bacteriófagos, cada um, expressando um peptídeo diferente, e cada bacteriófago carrega uma sequência de DNA codificante para o peptídeo expresso, representando um clone; cada clone presente na biblioteca pode ser propagado individualmente expressando o mesmo peptídeo (61). 
A eficácia da seleção por Phage Display está diretamente relacionada com a complexidade da biblioteca utilizada (quanto maior for a diversidade de clones contendo peptídeos distintos dentro da biblioteca, maior a probabilidade de se encontrar um ligante afim à molécula alvo). Uma biblioteca de Phage Display pode conter mais de $10^{10}$ diferentes peptídeos o que resulta em ligantes para virtualmente qualquer alvo biológico $(57,63)$.

Entre as vantagens da utilização do Phage Display podemos citar a ligação direta que existe entre fenótipo experimental e genótipo encapsulado, mostrando a evolução dos ligantes selecionados até moléculas otimizadas (54), a habilidade de selecionar ligantes de alta afinidade, a possibilidade de produzir proteínas solúveis, o baixo custo e fácil manuseio (59). Esta técnica pode levar a produção de uma alta variedade de ligantes, incluindo anticorpos recombinantes e peptídeos. Além disso, pode beneficiar diagnóstico através da produção de moléculas. Essas características do Phage display permitem identificar alvos terapêuticos e diagnósticos relevantes aos diversos processos biológicos de um organismo e isolar e caracterizar peptídeos antagonistas ou agonistas dos alvos identificados $(55,64)$.

Neste projeto, buscamos identificar através da tecnologia de Phage Display, moléculas ligantes do CD16 a Escherichia coli, que possam estar envolvidas no processo de inibição da fagocitose da mesma. 




\section{Objetivos}

\section{1- Objetivo Geral:}

Em função do conhecimento obscuro da fisiopatologia da sepse e a escassez de terapias eficazes, a identificação de proteínas envolvidas na interação de E. coli e CD16 poderão ser utilizadas na evolução e tratamento de pacientes sépticos, dado o fato de que a ligação entre CD16 e E. coli previne a fagocitose e promove a inflamação, efeito que pode ser bloqueado para induzir aumento da fagocitose e tratamento de doenças infecciosas, sendo este o objetivo principal do presente trabalho.

\section{2- Objetivos Específicos:}

- Selecionar e identificar peptídeos ligantes ao CD16 a E. coli. Utilizando a metodologia de Phage display, buscamos peptídeos que interagissem com CD16. A expectativa é que esses peptídeos mimetizem proteínas ligantes de CD16, em particular, proteínas de E. coli envolvidas na interação com CD16.

- Identificar e validar o papel dos pares peptídeo e proteínas ligantes de CD16 identificados, na indução da inibição das vias de fagocitose. Através de modelos in vitro, os peptídeos e suas proteínas ligantes de CD16 identificadas foram avaliados quanto ao papel na fagocitose agente infeccioso. 




\section{Métodos}

\section{1- Bibliotecas de Phage Display}

As bibliotecas utilizadas neste projeto foram produzidas no laboratório de Biologia Vascular do Instituto de Química da USP por Jussara Michaloski e Ricardo Giordano e cedidas gentilmente para o presente estudo utilizando-se o vetor fUSE55 e a metodologia desenvolvida por George Smith (52) com modificações para melhor eficiência e maior número de clones finais $(65,66)$. Em resumo, oligonucleotídeos sintéticos contendo o códon degenerado (NNK) $\mathrm{n}$ ( $\mathrm{n}$ = número de aminoácidos desejado; $\mathrm{N}$ = qualquer nucleotídeo e $\mathrm{K}=\mathrm{G}$ ou $\mathrm{T}$ ), flanqueados por sítios de restrição $\mathrm{Bgl}$ II foram obtidos comercialmente (Invitrogen). O inserto foi convertido em DNA dupla fita com Klenow DNA polimerase, digerido com $\mathrm{Bgl}$ II, ligado com T4 DNA ligase ao vetor fUSE55 previamente tratado com Bgl II, e transformado por eletroporação (entre 100 e 200 eletroporações individuais por biblioteca) em bactéria E.coli cepa MC1061.

As bibliotecas construídas foram do tipo X6, e CX8C (X representa qualquer aminoácido e $\mathrm{C}=$ cisteínas que permite criar bibliotecas cíclicas). O uso de bibliotecas lineares e cíclicas, e de diferentes tamanhos, foi empregado para aumentar a diversidade e a estabilidade estrutural de peptídeos disponíveis para o estudo. Fagos, individuais ou bibliotecas, foram cultivados por infecção bacteriana, crescimento em meio Luria-Bertani (LB) suplementado com Kanamicina $(100 \mu \mathrm{g} / \mathrm{ml})$ e Tetraciclina $(20 \mu \mathrm{g} / \mathrm{ml})$ e obtidos do sobrenadante da cultura pelo método da precipitação com $\mathrm{PEG} / \mathrm{NaCl}(67,68)$.

\section{2- Produção, purificação e titulação de fagos}

Os fagos foram isolados e purificados do sobrenadante de cultura de bactéria (E.coli MC1061), precipitados pelo método de PEG/NaCl (67), e 
ressuspendidos em PBS ( $\mathrm{pH}$ 7.4). Os fagos foram titulados por diluição seriada em meio LB, infecção em E.coli K91kan, e semeados em LB-ágar contendo tetraciclina $(20 \mu \mathrm{g} / \mathrm{mL})$ e Kanamicina $(100 \mu \mathrm{g} / \mathrm{mL})$. O número de unidades transdutoras de bactéria (TU) foi calculado contando-se as colônias obtidas.

\section{3- Ensaios de biopanning contra os alvos}

O alvo FcRyllla de camundongo (disponível comercialmente pela R\&D systems) foi imobilizado em placas de $96-$ poços ( $500 \mu \mathrm{g} / \mathrm{ml} \mathrm{em} \mathrm{PBS)} \mathrm{durante} \mathrm{a}$ noite a $4^{\circ} \mathrm{C}$, os poços foram lavados com PBS, bloqueados com PBS $3 \%$ BSA ou bloqueio vegetal $(\mathrm{BV})$ por 2 horas à temperatura ambiente e incubados com a biblioteca de fagos em PBS 3\% BSA ou BV. Após 2 horas à temperatura ambiente, os poços foram lavados 10 vezes com PBS, e os fagos ligados aos receptores imobilizados foram recuperados por infecção com E.coli K91kan. Diluições em série foram plaqueadas em meio LB-agar-tetraciclina/kanamicina para quantificação do número de fagos ligados a cada receptor (a ilustração dos ciclos de seleção está resumida na Figura 5). Ao final, os fagos obtidos foram sequenciados conforme descrito no item abaixo. 


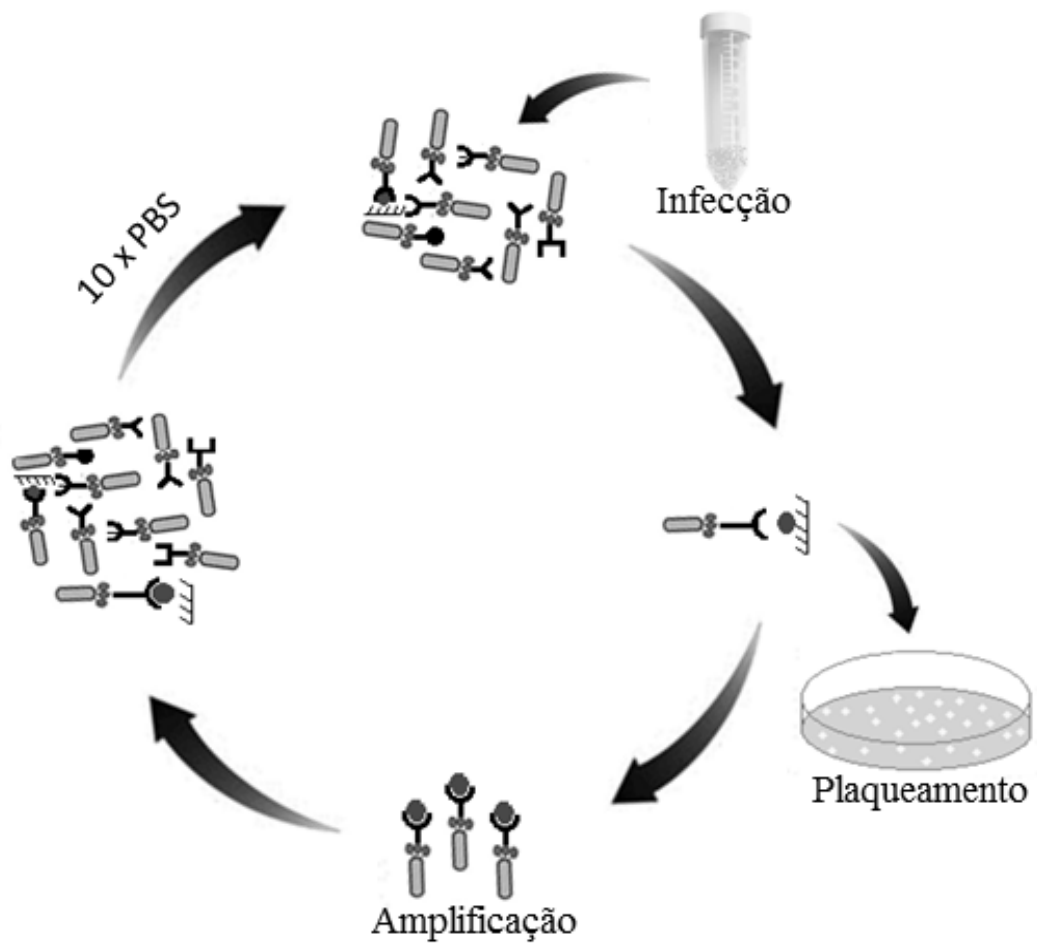

Figura 5. Biopanning. Esquema ilustrativo do Ciclo de seleção de fagos. Onde: $10 x P B S=10$ lavagens com o tampão PBS.

\section{4- Seleção de clones, PCR e sequenciamento para a determinação do peptídeo apresentado pelo fago.}

Ao final do biopanning, os fagos obtidos foram semeados em placas de LB-ágar-tetraciclina/kanamicina e as colônias individuais selecionadas foram e ressuspendidas em $50 \mu \mathrm{L}$ de PBS. A região do DNA codificante para o inserto de peptídeo foi amplificada a partir de $2 \mu \mathrm{L}$ desta suspensão em reação de PCR, utilizando-se os oligonucleotídeos específicos (forward 5'-CATGCC CGGGTA CCTTTC TATTCT C-3' e reverse 5'-CCCTCA TAGTTA GCGTAA CGATCT-3'), em termociclador por 35 ciclos (desnaturação $\left(94^{\circ} \mathrm{C}\right) 15$ segundos; anelamento $\left(60^{\circ} \mathrm{C}\right) 30$ segundos, extensão $\left(72^{\circ} \mathrm{C}\right) 1$ minuto). Os produtos de PCR foram sequenciados para identificação do peptídeo apresentado por cada fago selecionado. 


\section{5- Caracterização dos peptídeos identificados e seus receptores}

Os peptídeos identificados foram então priorizados para validar a interação do peptídeo com o receptor identificado. Inicialmente, os peptídeos isolados foram analisados por métodos de bioinformática, utilizando software disponíveis (ClustalW, Blast) em busca de motivos de aminoácidos presentes em mais de um dos peptídeos isolados. Os motivos identificados foram utilizados para varrer bancos de dados, em busca de peptídeos com similaridade significativa com proteínas conhecidas (similaridade com a estrutura primária).

\section{6- Ensaios de ligação Phage display (binding)}

Para validar a interação peptídeo-receptor, realizamos ensaios de ligação (binding). Os receptores (disponíveis comercialmente) foram imobilizados em placas de 96 -poços $\left(10 \mu \mathrm{g} / \mathrm{ml}\right.$ em PBS) durante a noite a $4^{\circ} \mathrm{C}$; os poços foram então lavados com PBS, bloqueados com PBS 3\% BSA ou BV (bloqueio vegetal) por 2 horas à temperatura ambiente e incubados com $10 \%$ $10^{10} \mathrm{TU}$ do fago a ser testado e de fagos controle (fd: sem inserto de peptídeo), ambos em PBS $3 \%$ BSA ou BV. Após 2 horas à temperatura ambiente, os poços foram lavados 10 vezes com PBS, e os fagos ligados aos receptores imobilizados foram recuperados por infecção com E.coli K91kan. Diluições em série foram plaqueadas em meio LB-ágar-tetraciclina para quantificação do número de fagos ligados ao receptor.

\section{7- Bioinformática estrutural}

Além da análise clássica por softwares conhecidos, a análise mais avançada foi realizada pelo Dr. Paulo Sérgio Lopes de Oliveira do Laboratório 
Nacional de Biociências (LNBio) que desenvolveu, através do método de modelagem molecular, uma base de dados com informações sobre mimotopos tridimensionais do proteoma de E.coli. A partir deste modelo, foram filtradas todas as proteínas de E.coli onde o peptídeo selecionado por Phage display (PD) apresentava similaridade sequencial com algum mimotopo putativo.

As estruturas 3D do proteoma de E. coli foram obtidas da base de dados ModBASE (69). A busca dos mimotopos foi conduzida filtrando-se todos os resíduos de superfície de cada uma das 3000 estruturas, utilizado um programa em linguagem Python (http://www.python.org) que importa o módulo YASARA (70). Foram selecionados resíduos que tivessem pelo menos $30 \%$ da superfície exposta ao solvente. Uma estrutura de grafo foi então utilizada para armazenar estes resíduos de superfície. Cada par de resíduos da superfície cujo carbono-alfa se encontrava a menos de $4 \mathrm{~A}$ de outro eram conectados por uma aresta. Em seguida, foram procurados todos os caminhos simples (sem ramificações entre dois vértices - inicial e final-, cujo o número de vértices entre eles fosse maior ou igual a 5). Isso permitiu encontrar mimotopos com pelo menos cinco aminoácidos. Todas as rotinas de grafos foram implementadas utilizado o módulo networkx (http://networkx.github.io/documentation/latest/index.html. As sequências dos peptídeos estruturalmente conectados (que poderiam ser contíguos ou não) foram armazenadas no formato FASTA. Este arquivo foi convertido para uma base de dados no formato do programa BLAST (71) usando programa formatdb, construindo assim a base de dados de mimotopos putativos do proteoma de E. coli. Em seguida o programa BLAST foi então utilizado para comparar os peptídeos selecionados por Phage display com a base de 
mimotopos putativos.

Dessa forma identificou-se um conjunto de proteínas putativas que poderiam conter os mimotopos experimentais.

Para a validação computacional das proteínas candidatas de $E$. coli encontradas pela comparação de mimotopos, foi estabelecido um protocolo que envolveu a análise da interação proteína candidata com CD16 através de docking geométrico corpo-rígido. Cada par de interação gerou dez possibilidades que foram avaliadas e ranqueadas de acordo com os seguintes critérios:

- Competição: em relação ao CD16, quantos resíduos que participam da interação com o anticorpo estão presentes na interação com a proteína alvo.

- $\quad$ Hit: em relação ao peptídeo selecionado, quantos resíduos estão presentes na interface.

Foi realizada essa avaliação para cada proteína (que pode ter tido mais de um peptídeo selecionado) e seu escore final é dado pela média da soma do escore de competição e hit. $\mathrm{O}$ valor obtido, que varia de 0 a 1 , indica quais proteínas alvo teoricamente podem estar participando da interação, impedindo que o CD16 se ligue ao anticorpo.

\section{8- ELISA (Ensaio de Ligação)}

Para confirmação da ligação entre peptídeos e receptores, foi realizada uma adaptação do ensaio ELISA (binding). Os peptídeos sintéticos para o ensaio foram adquiridos na empresa Chinese Peptide Company.

Inicialmente os peptídeos selecionados foram imobilizados em poços de 


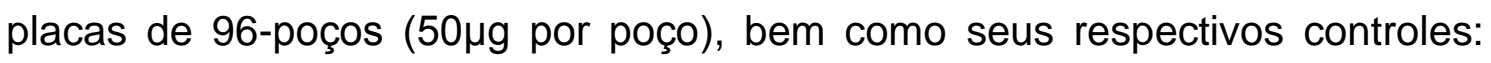
controle positivo $(\mathrm{lgG} 10 \mu \mathrm{g} / \mathrm{mL})$ e controle negativo $(\mathrm{BSA} 10 \mu \mathrm{g} / \mathrm{mL})$. Foram utilizados: PBS + $0.05 \%$ Tween20 para as lavagens e BSA $2 \%$ para bloqueio. Após a fase de fixação e bloqueio foram adicionados os receptores (CD16) em diversas concentrações e adição do anti-CD16 biotinilado. Após incubação aditou-se streptavidina conjugada a fosfatase alcalina para então procedermos com a leitura $(405 \mathrm{~nm})$. Além do binding com os peptídeos, realizamos uma adaptação do ELISA para verificarmos a ligação entre a E.coli mutada e E.coli wild type (K12) contra nossos receptores, a fim de elucidar a diferença da presença ou ausência da proteína identificada em relação à ligação ao CD16. A E.coli mutada (onde a proteína identificada está ausente) foi adquirida no banco de bactérias da Universidade de Yale/ USA (The Coli Genetic Stock Center). Para este binding, inicialmente as bactérias foram fixadas overnight na placa de 96 poços numa concentração de $10^{6}$ bactérias/poço. As mesmas condições, bem como controles, tampões e receptores foram usados.

\section{9-Validação dos pares peptídeos e proteínas ligantes do CD16 identificados}

Através de modelos in vitro, os peptídeos e suas proteínas ligantes de CD16 identificadas estão sendo avaliados quanto ao papel na fagocitose do agente infeccioso. A validação inicialmente está sendo realizada em mastócitos, através de modelos de indução (realizada no Laboratório INFLAMEX, coordenado pelo Dr. Renato Monteiro, na Universidade de Paris Diderot). A metodologia empregada é a estimulação de mastócitos (linhagem 
$\mathrm{RBL}$, rat basophilic leukemia) transfectada com CD16 humano chimera com a parte intracelular da cadeia gamma (clone FcyRIII- $\gamma$ ), também denominada de RBL 9.1, como descrito recentemente pela equipe francesa (39).

O ensaio para mensuração da liberação de $\beta$-hex ( $\beta$-hexosaminidase) está sendo realizado com células da linhagem RBL - 2H3 (RBL 9) e RBL 9.1. As células são mantidas em meio DMEM completo (15\% de soro fetal bovino, penicilina $100 \mathrm{UI} / \mathrm{mL}$, estreptomicina $0,1 \mathrm{mg} / \mathrm{mL}$ )e acondicionadas em estufa a $37^{\circ} \mathrm{C}$ e atmosfera com $5 \%$ de $\mathrm{CO} 2$ até alcançar confluência. As células são dissociadas utilizando tripsina $1 x$ e a suspensão celular centrifugada a 1500 rpm por 5 minutos e colocadas em placas de 96 poços na densidade $2,5 \times 10^{5}$ células/ml. Após um período de fixação de 2 horas das células (RBL) adicionamos $2 \mu \mathrm{l}$ de $\lg E$ 1/100. As células RBL são novamente incubadas por 18 horas, e após este período são adicionadas as bactérias wild type e mutada $\left(10^{7}\right)$ em diferentes poços (triplicata cada) e deixados incubando a $37^{\circ} \mathrm{C}$ por 2 horas. Passado o período de fixação, o sobrenadante é retirado e as células estimuladas ou não (controle) com DNP-HSA por 45 minutos e triton 10\% (controle positivo). Findado este período, $25 \mu \mathrm{l}$ são transferidos para nova placa, e são adicionados $50 \mu \mathrm{l}$ de pNAG $(1,3 \mathrm{mg} / \mathrm{ml})$ diluído em tampão citrato $0,05 \mathrm{M}$ pH 4,5 e incubado por 1hora e 30 minutos e após este período para a realização da leitura adita-se $150 \mu \mathrm{l}$ de glicina $0,2 \mathrm{M}$ pH10,7 (densidade óptica de $405 \mathrm{~nm})$.

As leituras das amostras do sobrenadante e do lisado são relacionadas entre si e o resultado é expresso em função da porcentagem de liberação de $\beta$ hexosaminidase por células RBL-9 e RBL-9.1. 
RESULTADOS 



\section{Resultados}

\section{1 - Pannings in vitro para identificação de alvos moleculares contra o receptor FcyRIIla (CD16a) de camundongo.}

Para identificarmos peptídeos ligantes de FcyRIIla (CD16a) duas bibliotecas de peptídeos foram escolhidas: uma contendo peptídeos pequenos (6 aminoácidos) e lineares (X6) e outra contendo peptídeos um pouco mais longos (8 aminoácidos) e cíclicos (CX8C). As bibliotecas de fagos CX8C e X6 foram incubadas in vitro com a proteína recombinante de camundongo porção extracelular do receptor FcyRIIIa (CD16).

Após lavagens com PBS, os fagos que se ligaram ao alvo foram recuperados por infecção bacteriana em E. coli K91kan, e amplificados em meio de cultura líquido LB durante 20 horas de crescimento bacteriano. Os fagos obtidos e amplificados no primeiro ciclo foram incubados com a proteína recombinante para novo ciclo de seleção. Nesta etapa os fagos não são plaqueados para quantificação, pois, em teoria, os fagos isolados são únicos e, ao quantificar por plaqueamento de bactéria, poderíamos perder peptídeos que ainda não foram amplificados. Assim, como o primeiro ciclo de seleção não é contabilizado ele não está representado no gráfico. O segundo, terceiro e quarto ciclos de seleção são semelhantes ao primeiro; nestes ciclos de seleção, cada fago expressando um determinado peptídeo já apresenta muitas cópias e parte dos fagos recuperados por infecção pode ser quantificado. Foram realizados quatro pannings usando BSA $3 \%$ como bloqueio (os quais foram descartados do nosso estudo por apresentar ligação do BSA com nosso receptor) e um panning usando BV (tampão de bloqueio vegetal) como bloqueio; todos os panning foram realizados até o quarto ciclo de seleção. A 
figura 6 apresenta os resultados do panning viável ao longo dos ciclos de seleção de fagos utilizando o BV.

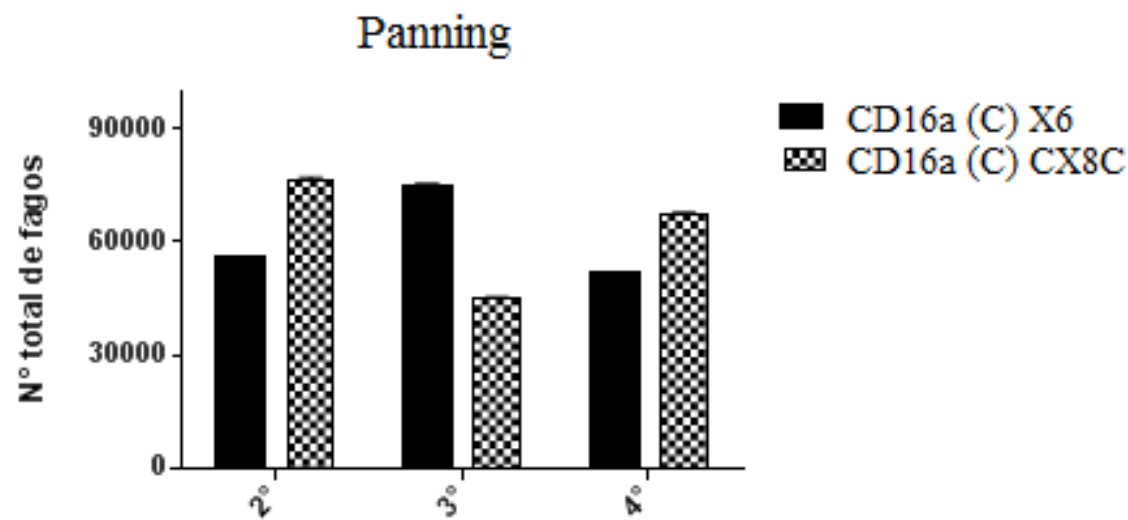

Ciclos de seleção

Fig 6. Phage Display in vitro contra o receptor FcyRllla de camundongo. $O$ gráfico mostra o número total de fagos recuperados em cada ciclo de seleção com as biblioteca de fagos CX8C e X6 e o receptor FCyRIIla de camundongo imobilizados in vitro. Assim representados nas legendas: CD16a (C) X6: FcyRIIla de camundongo incubado com biblioteca X6; CD16a (C) CX8C: FcyRIlla de camundongo incubado com biblioteca CX8C.

Dentre os resultados do sequenciamento de clones individuais de todos os biopanning, apenas o ensaio realizado com a biblioteca CX8C utilizando-se o bloqueio vegetal, resultou na seleção de 2 peptídeos únicos (Tabela 2). Estes peptídeos foram selecionados para validação e estudos por bioinformática.

\section{2- Sequenciamento e análise por Bioinformática}

Diversos fagos individuais que se ligaram a FcyRIlla de camundongo no quarto ciclo de seleção obtidos no panning foram selecionados (aleatoriamente) e a região que contém a sequência de DNA codificante para o peptídeo apresentado pelo fago foi amplificada por PCR. Para verificar a qualidade do DNA (e certificar-se que a reação de PCR funcionou) foi realizada verificação através de eletroforese em gel de agarose $2 \%$, corado com brometo de etídio. Após esta verificação, foi realizado o sequenciamento destes 
produtos. Ao todo foram sequenciados 40 fagos, 20 do grupo CD16a (C) X6 e 20 do grupo CD16a (C) CX8C. Destas 20 sequências do grupo CD16a (C) CX8C tivemos 2 sequências predominantes com 8 repetições (CFGAHGVFFC) e 9 repetições (CYWGGTEGAC), sendo que 3 sequências a qualidade estava ruim e não conseguimos visualizá-las. Tabela 2 e 3 . Já o sequenciamento do grupo CD16a (C) X6 teve apenas 1 sequências repetida (2vezes) (VGIPRW) de 17 sequências viáveis. Tabela 2 e 3 . Porém esta última sequência não validou e foi excluída dos estudos posteriores (dados não mostrados).

Assim a continuidade do nosso estudo foi direcionada para os dois peptídeos (CFGAHGVFFC, CYWGGTEGAC) provenientes do grupo CD16a (C) CX8C. Abaixo mostramos a análise do sequenciamento tomando como modelo o peptídeo CYWGGTEGAC gerado (Figura 7), seguindo os passos do resultado do sequenciamento analisados através do software BioEdit Alignment Editor e ExPasy Translate Tool.

\begin{tabular}{cc}
\hline CD16a (C) CX8C & CD16a (C) X6 \\
\hline FGAHGVFF & VGIPRW \\
FGAHGVFF & RFANWG \\
FGAHGVFF & FVRSAG \\
FGAHGVFF & KFFDNN \\
FGAHGVFF & LFFASS \\
FGAHGVFF & FAGYIG \\
FGAHGVFF & FRNVNS \\
FGAHGVFF & CCNYWS \\
YWGGTEGA & VGIPRW \\
YWGGTEGA & GSYRRL \\
YWGGTEGA & RLGREV \\
YWGGTEGA & IRCVTC \\
YWGGTEGA & LWRGRT \\
YWGGTEGA & HHGATS \\
YWGGTEGA & TAWFGP \\
YWGGTEGA & LWIDMY \\
YWGGTEGA & VMYAQA \\
\hline
\end{tabular}

Tabela 2. Peptídeos identificados após sequenciamento do DNA codificante. (Resultado do sequenciamento dos clones captados do Panning com BV). 


\begin{tabular}{cc}
\hline CD16a (C) CX8C & CD16a (C) X6 \\
\hline-- FGAHGVFF & -VGIPRW- \\
YWGGTEGA-- & -VGIPRW- \\
& -IWIDMY- \\
& VMYAQA-- \\
& -IWRGRT- \\
& -- HHGATS \\
& -- GSYRRI \\
& -- RIGREV \\
& -KFFDNN- \\
& -IFFASS- \\
& -RFANWG- \\
& -- FRNVNS \\
& -- FVRSAG \\
& -- FAGYIG \\
& TAWFGP-- \\
& -- IRCVIC \\
& -- CCNYWS \\
\hline
\end{tabular}

Tabela 3. Peptídeos alinhados usando o software ClustalW. 


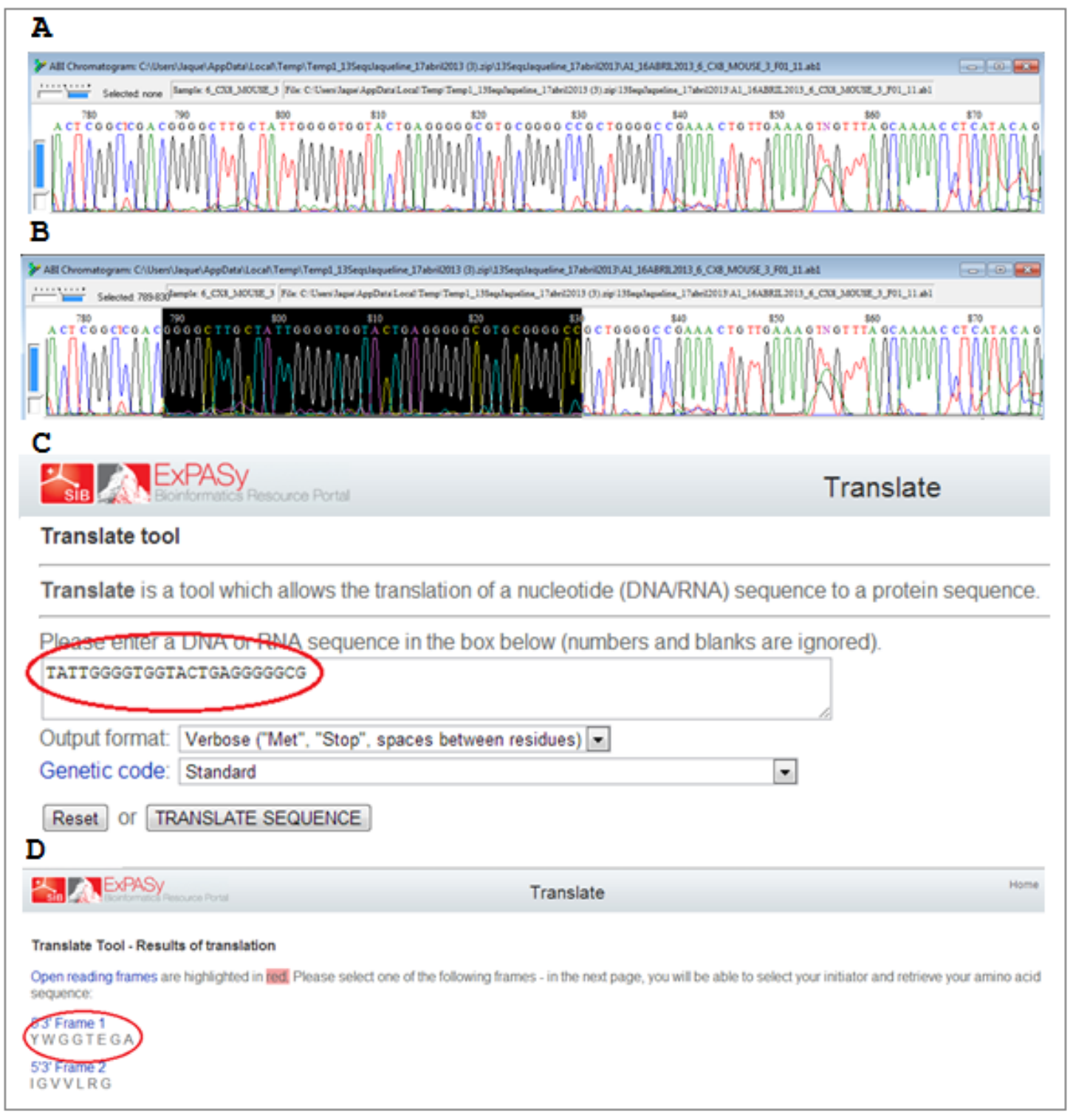

Figura 7 A,B,C,D. Análise do sequenciamento por Bioinformática. A) Análise do sequenciamento usando BioEdit Alignment Editor. Tendo como resultado a sequência do peptídeo CYWGGTEGAC. B) Continuação da análise do sequenciamento. (Seleção da região de interesse baseada nas regiões flanqueadoras) C) Tradução da sequência de DNA usando ExPasy Translate Tool. D) Continuação da tradução. Resultando no peptídeo selecionado.

Para identificar proteínas de E.coli que contenham as sequências identificadas nos biopannings e, portanto, possam ser ligantes de CD16, nós realizamos a comparação das sequências de peptídeos com bancos de proteínas através de alinhamentos locais por meio do software BLAST "Basic 
Local Alignment Search Tool' (Fig 8 e 9). A análise das peptídeos identificados (Grupo CD16a (C) CX8C) gerou descrições compatíveis com proteínas hipotéticas de E.coli.

\begin{tabular}{|c|c|c|c|c|c|c|c|}
\hline & Description & $\begin{array}{l}\text { Max } \\
\text { score }\end{array}$ & $\begin{array}{l}\text { Total } \\
\text { score }\end{array}$ & $\begin{array}{l}\text { Query } \\
\text { cover }\end{array}$ & $\underset{\text { value }}{E}$ & Ident & Accession \\
\hline & hypothetical protein [Escherichia colil > ablEHG01225.11 hypothetical protein 10102531 [Escherichia colic cloneA i1] & 24.4 & 24.4 & $100 \%$ & 13 & $73 \%$ & WP 001363441.1 \\
\hline 四 & phaqe immunity protein [Escherichia colli] > Qb|EGX03471.11 phage requlatory protein, Rha family protein [Escherichia coli STEC MHI813] & 23.5 & 23.5 & $70 \%$ & 30 & $86 \%$ & WP 000836740.1 \\
\hline 回 & racemase [Escherichia coli] >qb|E\|ll02028.1] aspartate racemase [Escherichia coli 96.154] & 21.8 & 21.8 & $70 \%$ & 101 & $86 \%$ & WP 000848660.1 \\
\hline$\square$ & glve protein [Escherichia coli DEC15E] & 21.4 & 21.4 & $60 \%$ & 127 & $100 \%$ & EHY15937.1 \\
\hline 四 & alvB, subunit of E\|IBCGIV, partial [Escherichia coli BL21(DE3)] >reffYP 006130970.11 hypothetical protein ECDH1ME8569 3569 [Escherich & 21.4 & 21.4 & $60 \%$ & 137 & $100 \%$ & YP 003001253.1 \\
\hline 四 & hypothetical protein [Escherichia coli] >ab|EOZZ70863.11 hypothetical protein G986 00312 [Escherichia coli UMEA 3682-1] & 21.4 & 21.4 & $70 \%$ & 138 & $86 \%$ & WP 021574989.1 \\
\hline$\square$ & PTS alucose transporter subunit IIA [Escherichia colil > qb|EFK23444.11 PTS system, alucose-like IIB component IEscherichia coli MS 187. & 21.4 & 21.4 & $60 \%$ & 138 & $100 \%$ & WP 001329469.1 \\
\hline 回 & PTS qucose transporter subunit $\|$ A [Escherichia colil> >ab|EFJ66631.11PTS system, alucose-like $\| B$ component [Escherichia coli MS 175 - & 21.4 & 21.4 & $60 \%$ & 138 & $100 \%$ & WP 001334838.1 \\
\hline 回 & PTS system, qlucose-like \|B component, partial [Escherichia coli]>Qb|EF J78942.11PTS system, qlucose-like \|B component, partial IEsch & 21.4 & 21.4 & $60 \%$ & 138 & $100 \%$ & WP 001328848.1 \\
\hline 四 & arbutin specific enzyme $\| B C$ component of PTS, partial [Escherichia coli] & 21.4 & 21.4 & $60 \%$ & 138 & $100 \%$ & WP 0013199361 \\
\hline
\end{tabular}

Figura 8. Descrição da análise no software BLASTp do peptídeo CFGAHGVFFC.

\begin{tabular}{|c|c|c|c|c|c|c|c|}
\hline & Description & $\begin{array}{l}\text { Max } \\
\text { score }\end{array}$ & $\begin{array}{l}\text { Total } \\
\text { score }\end{array}$ & $\begin{array}{l}\text { Query } \\
\text { cover }\end{array}$ & $\begin{array}{c}E \\
\text { value }\end{array}$ & Ident & Accession \\
\hline 四 & phosphotransferase enzyme family protein [Escherichia coli] > qb|EMV73679.11 phosphotransferase enzyme family protein [Escherichia co & 21.8 & 21.8 & $80 \%$ & 102 & $75 \%$ & WP 001674349.1 \\
\hline$\square$ & hypothetical protein [Escherichia colil > ab]EOQ54439.11 hypothetical protein WEW 02931 [Escherichia coli KTE33] >ab]EOU84156.11 hvpc & 21.4 & 21.4 & $70 \%$ & 135 & $71 \%$ & WP 016159543.1 \\
\hline$\square$ & hypothetical protein G893 00303 [Escherichia coli KOEGE 71 (186a)] & 21.4 & 21.4 & $70 \%$ & 135 & $71 \%$ & EQV95141.1 \\
\hline 田 & phage tail protein [Escherichia coli] > qb|ElL55227.1] hypothetical protein EC54115 10326 [Escherichia coli 541-15] > qb|ELF09294.11 hyp & 21.4 & 21.4 & $70 \%$ & 135 & $86 \%$ & WP 001162669.1 \\
\hline 回 & membrane protein [Escherichia coli] >ab|EHU17995.11 putative membrane protein [Escherichia coli DEC1B] & 21.4 & 21.4 & $70 \%$ & 137 & $86 \%$ & WP 001408309.1 \\
\hline$\square$ & inner membrane protein vieH [Escherichia coli HVH 162 (4-5627982)] & 21.0 & 21.0 & $50 \%$ & 190 & $100 \%$ & EQS75408.1 \\
\hline$\square$ & membrane protein [Escherichia colil > qb|EG|12820.11 inner membrane protein YieH [Escherichia coli M605] & 21.0 & 21.0 & $50 \%$ & 191 & $100 \%$ & WP 000937853.1 \\
\hline ] & type I restriction endonuclease subunit S [Escherichia colil > qb|EFU98942.1| tvpe I restriction modification DN & I 21.0 & 21.0 & $50 \%$ & 191 & $100 \%$ & WP 001340499.1 \\
\hline 四 & 709792 1 & 21.0 & 21.0 & $50 \%$ & 191 & $100 \%$ & WP 021576659.1 \\
\hline 1 & inner membrane protein vieH [Escherichia colil > $>$ blEOV45723.1] inne & 21.0 & 21.0 & $50 \%$ & 191 & $100 \%$ & WP 016262793. \\
\hline
\end{tabular}

Figura 9. Descrição da análise no software BLASTp do peptídeo CYWGGTEGAC.

Além das análises através de softwares como BLASTp e ClustalW a análise avançada por bioinformática foi realizada através de uma parceria com o LNBio do CNPEM.

\section{3- Phage display - Ensaio de Ligação (Binding)}

Para confirmar que os peptídeos selecionados (CFGAHGVFFC e CYWGGTEGAC) ligam-se ao CD16, realizamos ensaios de ligação com fagos que expressaram estes peptídeos. Neste ensaio, os CD16 (humano e de camundongo) foram imobilizados em placa e incubados com os fagos. Antes do 
ensaio, os fagos foram sequenciados para confirmar a sequência do inserto, e titulados, para então serem testados no ensaio de ligação.

O objetivo deste ensaio de ligação, era confirmar que a interação entre o peptídeo apresentado pelo fago e os receptores alvos do panning eram específicas. Os fagos que se ligaram aos receptores foram recuperados por infecção bacteriana, plaqueados em meio seletivo contendo tetraciclina e kanamicina e as unidades transdutoras de bactéria contadas.

Nossos resultados mostram que ambos os fagos testados, ligaram-se ao CD16/Fc recombinante como esperado. Não observamos ligação do fago controle Fd-tete, que não contem inserto. Ainda como um sinal de especificidade, não observamos forte ligação de nenhum peptídeo com os outros receptores de membrana irrelevantes (VEGF-R3, VEGF-R2 e Neuropilina).

Estes receptores foram escolhidos por serem, assim como o CD16, proteínas de membrana recombinantes produzidas em fusão com a porção Fc de Ig humana. Como estes receptores também apresentam a fusão da porção Fc da lg humana, estes resultados indicam que os fagos CFGAHGVFFC e CYWGGTEGAC ligam-se realmente ao CD16.

Porém como observamos na figura 10 a ligação mais forte ocorre por parte do peptídeo CYWGGTEGAC. Este peptídeo deu origem ao hit correspondente a proteína WzxE, (detalhado mais adiante) mostrando que esta proteína parece ser o alvo que buscávamos. Esta figura resume o resultado de três ensaios de ligação na forma de porcentagem de ligação entre os fagos e os receptores alvo (CD16) e controles. 


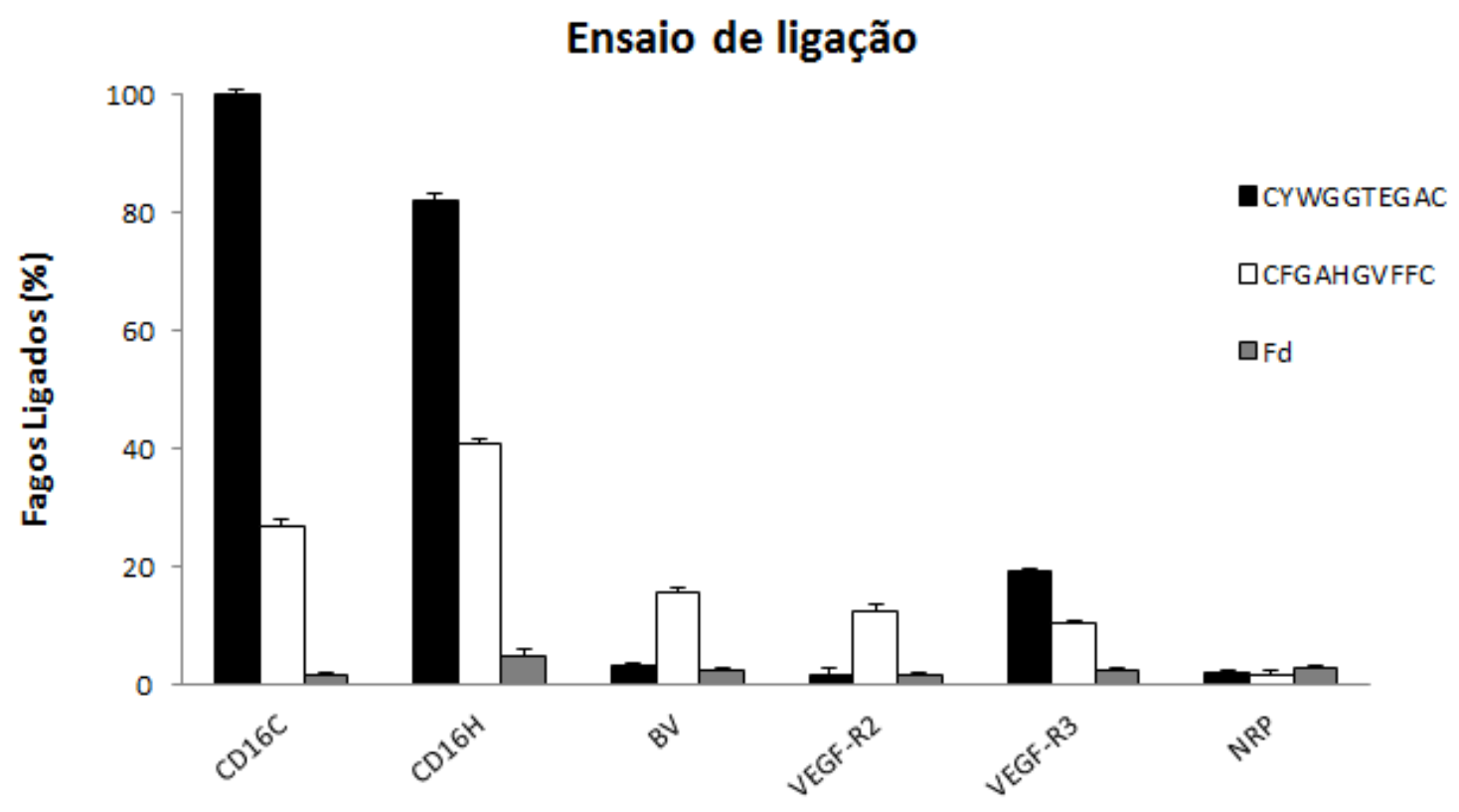

Figura 10. Ensaio de ligação dos fagos selecionados para validação frente aos receptores alvos (FcyRllla camundongo e FcyRllla humano). CD16C: FcyRIIla camundongo. CD16H: FcyRIIla humano. BV: bloqueio vegetal. VEGFR3: Fator de Crescimento Endotelial Vascular 3. VEGF-R2: Fator de Crescimento Endotelial Vascular 2. Fd: fago controle sem inserto. NRP: Neuropilina.

\section{4- Análise avançada por bioinformática}

Como mencionado na metodologia, o Dr Paulo Sérgio Lopes de Oliveira desenvolveu um banco com informações sobre as principais interações entre os peptídeos selecionados.

A partir do BLAST contra a database de superfícies, foram selecionados peptídeos com identidade maior ou igual a $50 \%$. Em seguida, foi identificada a qual proteína cada um dos peptídeos selecionados pertence.

Cada par de interação gerou dez possibilidades que foram avaliadas e ranqueadas de acordo a competição e o hit. Originando a lista de hits abaixo (Tabela 4): 


\begin{tabular}{|c|c|c|c|}
\hline UNIPROT & ESCORE & IDENTIFICAÇÃO & DESCRIÇÃO \\
\hline POAAA7 & 0.4902 & Proteína WzxE & $\begin{array}{l}\text { Bacterial outer membrane biogenesis; } \\
\text { Biossíntese do antígeno comum bacteriano. }\end{array}$ \\
\hline P64588 & 0.4827 & $\begin{array}{l}\text { Regulador } \\
\text { transcricional YqjI }\end{array}$ & $\begin{array}{l}\text { Reprime a expressão de YqjH que está envolvida na } \\
\text { homeostase do ferro sob condições de excesso de } \\
\text { níquel. Também reprime sua própria expressão. }\end{array}$ \\
\hline P31825 & 0.4056 & $\begin{array}{l}\text { tRNA1(Val) } \\
\text { (adenina(37)-N6)- } \\
\text { metiltransferase }\end{array}$ & $\begin{array}{l}\text { Células sem este gene mostram hipersensibilidade } \\
\text { hiperosmótica e, em menor grau, stress oxidativo. }\end{array}$ \\
\hline P77237 & 0.403 & $\begin{array}{l}\text { Lisa proteína } \mathrm{S} \\
\text { homóloga de profago } \\
\text { lambdóide Qin }\end{array}$ & Pertence à família das proteínas $\mathrm{S}$ de fago lambda. \\
\hline POAAS5 & 0.3657 & $\begin{array}{l}\text { YlbF proteína } \\
\text { descaracterizada }\end{array}$ & \\
\hline Q47129 & 0.3433 & $\begin{array}{l}\text { Ativador transcricional } \\
\text { FeaR }\end{array}$ & $\begin{array}{l}\text { Regulador positivo da tynA / maoA e feaB / padA; os } \\
\text { genes para o catabolismo de 2-feniletilamina. }\end{array}$ \\
\hline P76350 & 0.2961 & $\begin{array}{l}\text { Transportador } \\
\text { Shikimate }\end{array}$ & $\begin{array}{l}\text { Célula de membrana interna; Proteína de membrana } \\
\text { multi-pass }\end{array}$ \\
\hline P09391 & 0.2867 & $\begin{array}{l}\text { Rhomboid protease } \\
\text { GlpG }\end{array}$ & $\begin{array}{l}\text { serina-protease que catalisa a proteólise } \\
\text { intramembranar. }\end{array}$ \\
\hline P63417 & 0.2651 & $\begin{array}{l}\text { YhbS } \\
\text { acetiltransferase })\end{array}$ & Pertence à família acetiltransferase. \\
\hline P25534 & 0.1267 & $\begin{array}{l}\text { 2-octaprenyl-6- } \\
\text { metoxifenol } \\
\text { hidroxilase }\end{array}$ & $\begin{array}{l}\text { As células sem este gene são fotossensíveis e não são } \\
\text { capazes de crescer com uma fonte não fermentável de } \\
\text { carbono. Eles também não produzem ubiquinona, e } \\
\text { acumulam-se 2-octaprenylphenol e 2-octaprenyl-6- } \\
\text { metoxifenol }\end{array}$ \\
\hline
\end{tabular}

Tabela 4. Hits oriundos da análise por bioinformática

Analisando os resultados demonstrados na tabela, identificamos que a proteína WzxE, por possuir maior valor (escore) seria "teoricamente" a proteína alvo participante da interação E.coli versus CD16. O peptídeo oriundo do PD que deu origem a essa proteína foi o peptídeo previamente denominado como 3: CYWGGTEGAC. Através do peptídeo 3 encontramos um hit de blast com o mimotopo YGGYEGA de WzxE, que está na superfície. 


\section{5- ELISA (Ensaio de Ligação)}

O ensaio ELISA foi realizado com o objetivo de confirmar a ligação entre os peptídeos sintéticos e o receptor alvo (CD16a) Figura 11 e também de verificar a ligação entre as bactérias (Escherichia coli K12 wild type e mutada sem a proteína de interesse) Figura 12 e 13. Usamos como controle positivo a IgG murina e humana, e como controle negativo o tampão BSA.

\section{Binding peptídeos sintéticos}

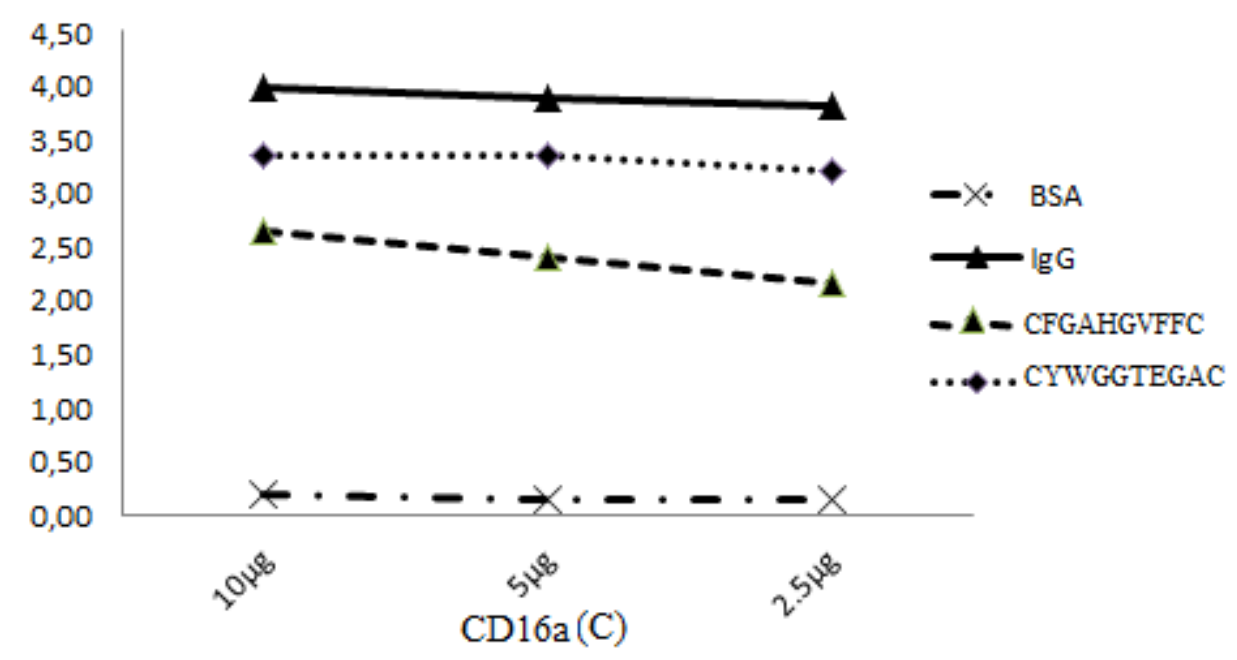

Figura 11. Ensaio de ligação (binding) dos peptídeos sintéticos ELISA. CD16a (C): FcyRllla camundongo. IgG: Imunoglobulina $G$ murina (controle positivo). BSA: albumina sérica bovina (controle negativo).

O ELISA realizado com os peptídeos sintéticos demonstra a ligação efetiva entre peptídeos CYWGGTEGAC e CFGAHGVFFC ao receptor CD16a; com uma intensidade maior de ligação entre o peptídeo CYWGGTEGAC e o CD16. 


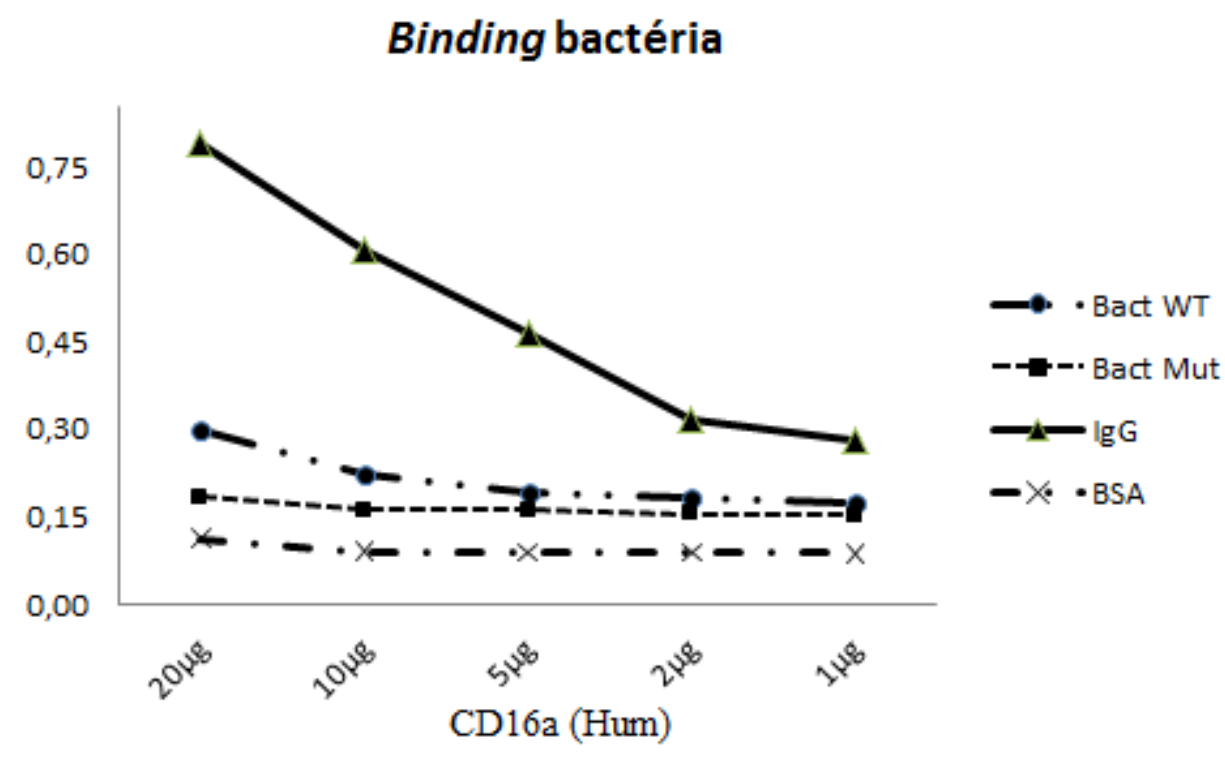

Figura 12. Ensaio de ligação (binding com receptor humano) da E.coli K12 wild type e mutada- ELISA. Bact WT: Escherichia coli wild type (K12). Bact Mut: Escherichia coli mutada (sem a proteína WzxE). IgG: imunoglobulina $G$ humana. BSA: albumina sérica bovina. CD16a (Hum): FcyRllla humano.

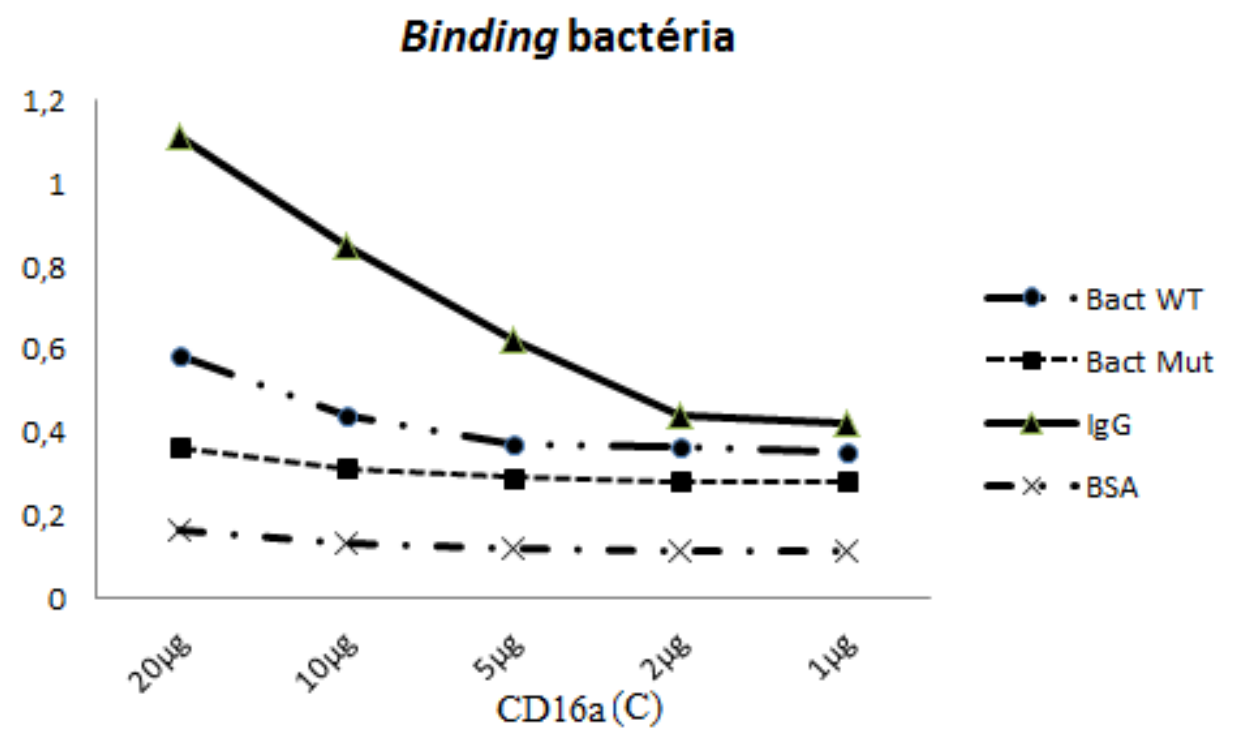

Figura 13. Ensaio de ligação (binding com receptor de camundongo) da E.coli K12 wild type e mutada- ELISA. Bact WT: Escherichia coli wild type (K12). Bact Mut: Escherichia coli mutada (sem a proteína WzxE). IgG: imunoglobulina G humana. BSA: albumina sérica bovina. CD16a (C): FcyRIlla camundongo.

O ELISA realizado com as bactérias mostrou que a bactéria wilde type tem uma ligação mais intensa que a bactéria mutada, acontecendo 
ao utilizarmos ambos os receptores alvo (CD16a humano e de camundongo) Fig 19 e 20). Este resultado sugere que a proteína identificada por bioinformática, baseada na identificação e seleção de peptídeos de E.coli por PD é o "alvo" responsável pela ligação entre Escherichia coli e o receptor Fc de Imunoglobulina G (FcyRIIla). 



\section{Discussão}

A síndrome da resposta inflamatória sistêmica (SIRS) causada por agente infeccioso (vírus, fungos, bactéria etc) é a denominação usada para definir sepse. Entre seus agentes etiológicos destacam-se as bactérias grampositivas e gram-negativas, responsáveis por 36\% e 35\% respectivamente das causas de sepse em todo mundo. Dentre as bactérias gram-negativas a Escherichia coli está entre os principais agentes infecciosos identificados em sepse $(1,8-12,72)$.

Sepse é uma doença grave, caracterizada por suas elevadas taxas de morbimortalidade e é considerada uma das maiores causadoras de morte em UTI em todo o mundo. Diversos estudos epidemiológicos demonstram a elevação da incidência dos casos de sepse nas últimas décadas, com decréscimo insatisfatório e inaceitável dessas taxas $(9,19)$.

Apesar dos inúmeros avanços em pesquisas, sua complexa patogênese continua ser pouco compreendida, e por todos os motivos aqui já citados a sepse pode ser considerada um dos principais desafios atuais da medicina, justificando os investimentos no desenvolvimento e avaliação de terapias e também na busca por uma maior elucidação da resposta imuno-inflamatória a ela associada $(3,8,20)$

Este projeto iniciou com o intuito de elucidarmos um pouco mais o papel do receptor Fc de imunoglobulina G (FcyR), em especial o FcyRIIla na sepse. Dando continuidade aos estudos do nosso grupo em que foi demostrado que a E. coli ao ligar-se ao CD16 tem seu mecanismo de fagocitose inibido, assim, nosso principal objetivo era identificar qual o meio de ligação entre $E$. coli e CD16a que poderia estar envolvido neste processo. 
Resumidamente: fagocitose é um processo ativo, mediado por receptores, que tem por finalidade a remoção de restos celulares e agentes patogênicos do organismo, ocorrendo por meio da internalização pela membrana da célula fagocítica em um vacúolo denominado fagossomo. Essa internalização depende da interação da célula e do microorganismo, podendo ocorrer através do reconhecimento de padrões associados ao patógeno (PAMP), por receptores de reconhecimento padrões (PRR) ou por meio de opsoninas, esta última, mediada por receptores Fc de imunoglobulina G (FcyR) ou receptores do complemento. O modelo de fagocitose que envolve a internalização de partículas opsonizadas por IgG via FcyR pode ser brevemente descrito em três principais passos: 1) inicialmente ocorre a ligação das partículas opsonizadas ao receptor 2) a cascata de sinalização intracelular é induzida 3) ocorre a formação de pseudópodos que englobam as partículas (73-75). Este processo complexo é acompanhado de sinalização intracelular que deflagra o rearranjo do citoesqueleto, ativação de mecanismos de morte intracelular, produção de quimiocinas e citocinas pró e anti-inflamatórias, apoptose entre outros (76).

Apesar de a fagocitose ser um processo ativo e complexo, muitas vezes é ineficiente. Cada vez, se sabe mais a respeito dos diversos mecanismos desenvolvidos por microrganismos patogênicos para burlar o sistema imune, reduzindo então a eficácia da fagocitose assim como a morte intracelular (77).

O surgimento de processos infecciosos em um indivíduo envolve complexas interações entre o microrganismo e o hospedeiro. Os principais eventos durante este processo incluem a entrada do microrganismo, o reconhecimento, a colonização, a invasão nos tecidos e células do hospedeiro, 
a evasão do sistema imune, o dano funcional e/ou tecidual. Em parte, a patogenicidade dos agentes infecciosos está relacionada à sua capacidade de resistir à imunidade $(77,78)$.

Diversos microrganismos patogênicos desenvolveram inúmeras estratégias para camuflar sua presença, burlando o sistema imune de seus hospedeiros. Ao que se sabe, estes microrganismos utilizam uma combinação de múltiplas estratégias de escape, inibindo assim o processo de fagocitose e morte intracelular; isso se dá em partes, pela destreza em modular o ataque pelo sistema imune, evadindo as linhas de defesa do hospedeiro.

Vários microrganismos expressam proteínas (na sua maioria, proteínas de superfície) que mimetizam moléculas das células hospedeiras com capacidade de interagir entre elas. A identificação destas proteínas bacterianas envolvidas na interação com estes receptores celulares é de grande importância, representando alvos para o desenvolvimento de estratégias terapêuticas e /ou preventivas que possam interferir no processo de evasão imune bacteriano.

Muitos agentes infecciosos possuem estratégias para escapar da ação do sistema imune, podemos citar como exemplo a resistência à fagocitose por neutrófilos pela Leptospira, além disso, sugere-se que as leptospiras utilizam da internalização em macrófagos como um dos mecanismos de escape do sistema imune e que esta etapa é essencial para o início da infecção. Além da resistência à fagocitose o escape do sistema complemento se dá através da aquisição de proteínas reguladoras do sistema ou por expressão de proteínas inibitórias (79-81). Outros agentes que resistem à fagocitose incluem o gênero Yersinia que são membros da família Enterobacteriaceae, abrangendo as 
espécies Yersinia pestis, Yersinia pseudotuberculosis e Yersinia enterocolítica Essas três espécies, apesar de causarem distintas manifestações no hospedeiro têm em comum a capacidade de resistir à fagocitose, além disso, ambas possuem tropismo pelo sistema linfático $(49,50,82)$.

Sabe-se também, que as EPECs, (subclasse das Escherichia coli) causadora de diarréia infantil, principalmente no primeiro ano de vida, possui um mecanismo que diminui sua internalização, inibindo a sinalização dependente de PI 3-quinase, via sistema de secreção tipo III (SSTT). Sistemas de secreção são dispositivos moleculares que permitem às bactérias exportar para o interior das células hospedeiras, proteínas efetoras. No SSTT, proteínas são introduzidas na célula hospedeira, e uma vez no interior da célula, essas proteínas interagem com domínios de proteínas do hospedeiro, por meio da fosforilação ou transferência de resíduos, que, em geral, resultam em uma cascata de reações que promovem modificações no citoesqueleto, evasão do sistema imune, morte e outras alterações celulares (83-85).

O principal mecanismo de virulência das EPECs se dá pela aderência ao enterócito, e consequentemente destruição das microvilosidades das células do hospedeiro, conhecidas como lesões AE ("attaching and effacing"). Os genes necessários para causar essa lesão estão localizados em uma PAI ("pathogenicity islands,"), e é denominado de LEE ("locus of enterocyte effacement'). Tal sistema possui como fatores de virulência EspA, EspB e EspD, além de proteínas efetoras que agem no citosol da célula hospedeira. EspA forma organelas que propiciam a forte aderência da bactéria à superfície celular do hospedeiro. EspB e EspD são translocados para a célula a ser 
invadida e formam poros na sua membrana, onde as proteínas efetoras são injetadas. (86-88).

A função ou o alvo da molécula efetora que é translocada por esses sistemas é que vai determinar a estratégia de virulência de um microrganismo, mesmo que o sistema seja semelhante entre diversas espécies. Geralmente as proteínas exportadas facilitam danos às células hospedeiras, propiciando a resistência e multiplicação bacteriana. Assim, podemos dizer que os sistemas de secreção são essenciais para a patogenicidade dos microrganismos.

\section{1- Identificação de peptídeos e proteínas ligantes de CD16a}

Diante do exposto e resultados acima, juntando com a complexidade da doença bem como dos mecanismos imunes envolvidos, somado a carência de conhecimento na área, nos levaram a propor um estudo sobre fagocitose em processos infecciosos e inflamatórios envolvendo a E.coli, por ser tratar de uma das bactérias mais comuns nestes episódios.

No presente estudo, baseado nos resultados prévios, mostramos uma expectativa para que o desfecho desta doença em relação ao seu tratamento possa melhorar.

Nossa expectativa era selecionar e identificar peptídeos e proteínas ligantes ao CD16 como discutido abaixo e após isto (etapa em andamento) validar esses peptídeos e proteínas através de modelos de inflamação e infecção.

Para atingir este objetivo, utilizamos a metodologia do phage display, que permite identificar pequenos peptídeos (6-10 aminoácidos) ligantes de virtualmente qualquer alvo biológico. Como muitas vezes os peptídeos 
mimetizam ligantes naturais dos alvos em estudo (67), nossa expectativa era que peptídeos ligantes de CD16 apresentassem sequências semelhantes a de proteínas de superfície de E.coli e que essas proteínas fossem receptores para CD16 envolvidos na sepse.

Tivemos várias dificuldades para realizar a seleção. Uma delas foi o uso de BSA, proteína comumente utilizada como agente de bloqueio em ensaios biológicos, tais como o phage display. Após várias tentativas de biopannings, notamos que o BSA comercial que utilizamos ainda continha quantidades significativas de Igs (imunoglobulinas), ligantes de CD16. Acreditamos assim, que 0 agente de bloqueio estivesse competindo com os fagos da biblioteca pela ligação ao receptor imobilizado. Por isso, mudamos o agente de bloqueio para o VBB (vegetal blocking buffer), que contém proteínas vegetais sem nenhum traço de Igs. Com esta troca, finalmente, conseguimos realizar os biopannings e selecionar peptídeos ligantes de CD16 como mostrados na tabela 2.

Após realizarmos a identificação dos peptídeos, utilizamos softwares de bioinformática para elucidar nossos achados, e identificamos similaridade entre as sequências CFGAHGVFFC e CYWGGTEGAC com proteínas hipotéticas de E.coli e proteínas de membrana de E.coli o que nos animou diante dos achados. Além disso, nossos peptídeos foram analisados por programas mais avançados de bioinformática.

Nesta análise, identificamos um hit de blast do peptídeo (CYWGGTEGAC) oriundo do PD com o mimetopo YGGYEGA de WzxE, dessa maneira foi realizada a identificação da proteína da E.coli. 
Esta proteína de membrana participa na translocação de carboidratos do interior para o exterior da célula. Se esta proteína está induzindo inibição do CD16, seria provavelmente através da apresentação de um carboidrato ao receptor. Porém, ainda não há documentação desta ação.

Outra possibilidade é que a interação do peptídeo mimetiza a ligação com IgG, como observado no passado que em determinadas condições a própria $\lg G$ induz $o$ sinal inibitório, deflagrado pela $E$. coli (39).

Através das técnicas utilizadas (parte da validação), o peptídeo CYWGGTEGAC, que foi o peptídeo que deu origem ao hit da proteína WzxE da Escherichia coli, apresentou um binding mais forte que o peptídeo CFGAHGVFFC, como demonstrado nos ensaios (binding oriundo do PD e ELISA) confirmando de que realmente é um ótimo candidato e de que a proteína identificada parece realmente interferir na ligação entre Escherichia coli e CD16.

A tecnologia empregada neste projeto tem sido uma inovação em estudos deste tipo. A utilização de bibliotecas de peptídeos apresentados em fagos para o encontro de ligantes para enzimas, anticorpos, moléculas protéicas entre outros, é o resultado desta técnica simples e efetiva. Mesmo os fagos que apresentam poucos peptídeos em sua superfície podem ser utilizados como ferramentas para analisar, e clonar a proteína de interesse com boa eficiência (92-94).

Com base nos dados da literatura e devido ao fato de que o Dr Ricardo Giordano tem uma vasta experiência nesta tecnologia acreditamos que a metodologia escolhida para o presente projeto tenha sido adequada, uma vez 
que já foi demonstrado em outros estudos que sequências peptídicas que reconhecem altas quantidades de ligantes como anticorpos monoclonais, receptores, proteínas, carboidratos foram identificados com sucesso após seleção por Phage display (95-97).

A continuidade da caracterização e validação dos peptídeos provenientes da seleção e identificação realizada após os ensaios de biopanning e binding, poderá ainda fornecer um melhor entendimento da interação patógenos (E.coli) - hospedeiro (CD16), bem como a descobertas de novos alvos biológicos que sirvam em estratégias terapêuticas futuras. Esta validação está sendo realizada através de modelos in vitro (fase em andamento) e futuramente in vivo; os peptídeos e suas proteínas ligantes de CD16 identificadas serão avaliados quanto ao papel na fagocitose do agente infeccioso.

A validação inicialmente será realizada em mastócitos (como citado na metodologia) através de modelos de indução (fase em andamento), seguida do uso dos peptídeos bacterianos in vivo, da proteína isolada e da E.coli mutada em modelos inflamatórios e de sepse.

\section{2 - LPS, antígeno 0 e proteínas Wzx}

O lipopolissacarídeo (LPS) está presente na parede de bactérias Gram negativas e caracteriza-se como uma molécula tripartida. É constituído de uma porção de polissacarídeo ligado covalentemente com o lipídeo A (LA) que representa o princípio endotóxico do LPS, e está ancorado na membrana externa da bactéria, além do LA, apresenta um grupo de oligossacarídeos e outro de polissacarídeos, formando as cadeias laterais denominadas de 
antígeno $\mathrm{O}$ (ou cadeia-O específica), a qual é característica e única para cada sorotipo bacteriano onde, geralmente é composto por uma sequência de oligossacarídeos idênticos (de 3 a 8 monossacarídeos cada) (98-101).

O antígeno $\mathrm{O}$, é considerado fator de virulência bacteriano, sendo alvo importante de ambos os sistemas imunes: inato e adaptativo, desempenhando um papel importante nas interações com o hospedeiro. Como citado, é responsável pela especificidade antigênica da estirpe e determina o sorogrupo O. A designação de sorogrupos é importante para a classificação, por exemplo, de cepas de E. coli, para estudos epidemiológicos, facilitando a ligação com a fonte de infecção (102). O antígeno O é extremamente variável, com mais de 186 formas em Escherichia coli. Existem quatro sistemas descritos como responsáveis pela exportação e montagem final do antígeno $\mathrm{O}$, entre eles 0 sistema Wzx/Wzy (103).

Este sistema (Wzx/Wzy) é o mais comum para a síntese dos polissacarídeos da superfície das células, que envolve a síntese, na face citoplasmática da membrana celular, de unidades de repetição, os quais são em seguida translocadas para a face periplasmática por uma translocase Wzx e depois polimerizado por Wzy para gerar o polissacarídeo (antígeno O) que é então incorporado ao lipopolissacarídeo (LPS) (104).

Tanto em bactérias Gram-negativas quanto em Gram-positivas, a maioria dos polissacarídeos da superfície celular são produzidos, através da via dependente Wzx/Wzy; estes glicanos incluem antígeno $\mathrm{O}$, antígeno comum enterobacteriano, exopolissacarídeo, revestimento de esporos, e cápsula em diversas bactérias. Os principais componentes desta via de montagem são a proteína de membrana interna Wzx flipase, Wzy polimerase e proteínas 
reguladoras de comprimento de cadeia WZZ, esta última pouco caracterizada até o momento (105)

As flipases Wzx são essenciais para a montagem do polissacarídeo da superfície celular bacteriana e são importantes para a sobrevivênca e virulência das espécies. São responsáveis pela translocação de unidades de repetição de açúcar ligada em lipídeos em toda a membrana interna e além de facilitarem a difusão passiva recentemente mostrou-se ser importante no transporte ativo secundário (106).

Dentre as flipases (ou também denomindas "translocases") destacamos a proteína WzxE. Esta proteína é também uma proteína de membrana cuja função primária é facilitar o transporte de moléculas através da membrana biológica com papel tanto na membrana quanto no citocromo, e é designada como translocase do antígeno-O e translocase do lipídeo III, estando envolvida no transporte de elétrons. Está presente em várias bactérias incluindo cepas diversas de E.coli como K12_MG1655, BW2952, K12_DH108, K12_W3110 etc (107-109).

Tomados em conjunto todos os dados bibliográficos aqui citados, juntamente com a recente identificação da proteína WzxE, como forte candidata responsável pela ligação entre receptores Fc de Imunoglobulina G (CD16a) e Escherichia coli, novas perspectivas em relação a futuros tratamentos para sepse e para doenças auto-imunes CD16 dependente parecem tomar forma. Cabe-nos agora, validar o papel destes peptídeos selecionados e da proteína identificada na fagocitose da E.coli. Após esta validação, poderemos quem sabe, utilizar tal achado como meio de bloqueio do 
receptor, inibindo a interação patógeno-hospedeiro, propiciando o aumento na capacidade fagocítica.

Muitas são as vantagens em usar pequenos peptídeos como medicamento. Peptídeos têm características desejáveis como baixa toxicidade, alta especificidade. Podem ser modificados para melhorar suas propriedades biológicas e farmacodinâmicas e possuem um custo de produção mais baixo que anticorpos monoclonais e proteínas recombinantes.

Coletivamente, os dados apresentados e discutidos neste trabalho, mostram que a proteína identificada WzxE expressa na membrana de Escherichia coli, juntamente com os peptídeos selecionados CYWGGTEGAC (que originou o hit para esta proteína) e CFGAHGVFFC formam bases para a elucidação da ligação patógeno - E.coli e hospedeiro - CD16. Além disso, estes peptídeos selecionados podem permitir o desenvolvimento de futuras terapias dirigidas a doenças CD16 dependentes e a sepse, sendo esse nosso maior objetivo.

Finalizo a tese sugerindo que este poderá ser um novo tratamento para a sepse causada por E.coli. Acreditamos que futuramente, o tratamento da sepse será mais individualizado, dependendo do agente, características genéticas e perfil clínico do paciente. 



\section{CONCLUSÕES}





\section{Conclusões}

- Através da técnica de Phage display, que é uma técnica de clonagem, que permite a expressão de diversas sequências de peptídeos na superfície de bacteriófagos (fagos), e a seleção destas, com base na afinidade por uma molécula-alvo, selecionamos por meio de biopanning 2 peptídeos ligantes à nossa molécula alvo (CD16).

- Após esta seleção, realizamos ensaios de ligação dos fagos (binding) e dos peptídeos sintéticos (ELISA) para verificar se os peptídeos selecionados realmente se ligavam à nossa molécula alvo. Ambos os ensaios de ligação foram confirmados. Sugerindo serem estes, futuros alvos terapêuticos.

- Identificamos por meio de bioinformática a proteína de E.coli (WzxE) a qual o peptídeo selecionado está relacionado.

- Com os resultados de ligação positivos e a identificação da proteína de interesse, adquirimos E.coli mutada (sem a proteína) e passamos a realizar ensaios validação in vitro para verificarmos o papel da proteína (fase em andamento).

- Nossos resultados somados à continuidade da validação dos dados obtidos podem confirmar a identificação de proteínas capazes de induzir inibição de fagocitose através do receptor CD16, assim poderemos usar os peptídeos e a proteína identificada como uma nova forma de tratamento da sepse, bem como, explorada no tratamento de doenças autoimunes, haja vista que estas proteínas também podem aumentar resposta inflamatória CD16-dependente. 




\section{Referências}

1. Silva E, Pedro Mde A, Sogayar AC, Mohovic T, Silva CL, Janiszewski M, et al. Brazilian Sepsis Epidemiological Study (BASES study). Crit Care. 2004 Aug;8(4):R251-60.

2. Abraham E, Matthay MA, Dinarello CA, Vincent JL, Cohen J, Opal SM, et al. Consensus conference definitions for sepsis, septic shock, acute lung injury, and acute respiratory distress syndrome: time for a reevaluation. Crit Care Med. 2000 Jan;28(1):232-5.

3. Angus DC, Linde-Zwirble WT, Lidicker J, Clermont G, Carcillo J, Pinsky MR. Epidemiology of severe sepsis in the United States: analysis of incidence, outcome, and associated costs of care. Crit Care Med. 2001 Jul;29(7):1303-10.

4. Silva FP, Velasco IT; Sepse, 1ㄹed. São Paulo: Manole. 2007.

5. Parker MM, Ognibene FP, Parrillo JE. Peak systolic pressure/endsystolic volume ratio, a load-independent measure of ventricular function, is reversibly decreased in human septic shock. Crit Care Med. 1994 Dec;22(12):1955-9.

6. Bohuslav J, Kravchenko VV, Parry GC, Erlich JH, Gerondakis S, Mackman N, et al. Regulation of an essential innate immune response by the p50 subunit of NF-kappaB. J Clin Invest. 1998 Nov 1;102(9):1645-52.

7. Moore FA, Moore EE, Read RA. Postinjury multiple organ failure: role of extrathoracic injury and sepsis in adult respiratory distress syndrome. New Horiz. 1993 Nov;1(4):538-49

8. Angus DC, Wax RS - Epidemiology of sepsis: an update. Crit Care Med, 2001;29;(Suppl7):S109-S116.

9. Friedman G, Silva E, Vincent $\mathrm{JL}$ - Has the mortality of septic shock changed with time? Crit Care Med, 1998;26:2078-2086.

10. Levy MM, Fink MP, Marshall JC, Abraham E, Angus D, Cook D, et al. SCCM/ESICM/ACCP/ATS/SIS International Sepsis Definitions Conference. Crit Care Med 2003;31:1250-6.

11. Leclerc F, Martinot A, Fourier C. Definitions, risk factors, and outcome of sepsis in children. In: Tibboel D, van der Voort E, editores. Update in Intensive Care and Emergency Medicine 25. Intensive care in Childhood. A Challenge to the Future. Berlin: Springer-Verlag; 1996. p. 227-38.

12. Pollack M, Ohl CA. Endotoxin-based molecular strategies for the prevention and treatment of gram-negative sepsis and septic shock. Curr Top Microbiol Immunol. 1996;216:275-97. 
13. Grinnell BW, Joyce D. Recombinant human activated protein C: a system modulator of vascular function for treatment of severe sepsis. Crit Care Med. 2001 Jul;29(7 Suppl):S53-60; discussion S-1.

14. Van den Berghe G, Wilmer A, Hermans G, Meersseman W, Wouters PJ, Milants I, Van Wijngaerden E, Bobbaers H, Bouillon R. Intensive insulin therapy in critically ill patients. N Engl J Med. 2006 Feb 2;354(5):449-61.

15. Bone RC. Sepsis, the sepsis syndrome, multi-organ failure: a plea for comparable definitions. Ann Intern Med. 1991 Feb 15;114(4):332-3.

16. Rivers E, Nguyen B, Havstad S, Ressler J, Muzzin A, Knoblich B, Peterson E, Tomlanovich M; Early Goal-Directed Therapy Collaborative Group. Early goal-directed therapy in the treatment of severe sepsis and septic shock. N Engl J Med. 2001 Nov 8;345(19):1368-77.

17. Bone RC. Sir Isaac Newton, sepsis, SIRS, and CARS. Crit Care Med. 1996;24:1125-8.

18. Proulx F, Fayon M, Farrell CA, Lacroix J, Gauthier M. Epidemiology of sepsis and multiple organ dysfunction syndrome in children. Chest. 1996;109:1033-7.

19. Martin GS, Mannino DM, Eaton S, Moss M. The epidemiology of sepsis in the United States from 1979 through 2000. N Eng J Med. 2003;348:1546-54.

20. Angus DC, Linde-Zwirble WT, Lidicker J, Clermont G, Carcillo J, Pinsky MR. Epidemiology of severe sepsis in the United States: analysis of incidence, outcome, and associated costs of care. Crit Care Med. 2001;29:1303-10.

21. Ventetuolo, CE and Levy MM. Biomarkers: diagnosis and risk assessment in sepsis. Clin Chest Med. 2008 Dec;29(4):591-603

22. Goldsby RA, Kindt TJ, Osborne BA., Imunologia de Kuby, 6 ${ }^{\mathrm{a}}$ Ed. Porto Alegre: Artmed. 2008.

23. Bruhns $\mathrm{P}$, lannascoli $\mathrm{B}$, England $\mathrm{P}$, Mancardi DA, Fernandez N, Jorieux $S$, Daëron M. Specificity and affinity of human Fcgamma receptors and their polymorphic variants for human IgG subclasses. Blood. 2009; 113:3716-25.

24. Ravetch JV, Kinet JP. Fc Receptors. Annu Rev Immunol. 1991;9:45792. 
25. Galon J, Bouchard C, Fridman WH, Sautès C. Ligands and biological activities of soluble Fc gamma receptors. Immunol Lett. 1995 Jan;44(23):175-81.

26. Daëron M. Fc receptor biology. Annu Rev Immunol. 1997;15:203-34.

27. Ravetch JV1, Clynes RA. Divergent roles for Fc receptors and complement in vivo. Annu Rev Immunol. 1998;16:421-32.

28. Kubagawa $\mathrm{Y} 1$, Honjo K, Kang DW, Kubagawa $\mathrm{H}$. Monoclonal Antibodies Specific for Human IgM Fc Receptor Inhibit Ligand-binding Activity. Monoclon Antib Immunodiagn Immunother. 2014 Dec;33(6):393-400.

29. Li X, Ptacek T S, Brown E E and Edberg J C. Fcy receptors: structure, function and role as genetic risk factors in SLE. Genes Immun. 2009 Jul;10(5):380-9.

30. Pradhan V, Patwardhan M, Ghosh K. Fc gamma receptor polymorphisms in systemic lupus erythematosus and their correlation with the clinical severity of the disease. Indian J Hum Genet. 2008 Sep;14(3):77-81.

31. Gessner JE, Heiken H, Tamm A, Schmidt RE. The IgG Fc receptor family. Ann Hematol 1998; 76: 231-48.

32. Ravetch JV and Bolland S. IGG FC RECEPTORS. Annual Review of Immunology. 2001.Vol. 19: 275-290.

33. Lin S, Cicala $C$, Scharenberg A M, Kinet J P. The FcعRI $\beta$ Subunit Functions as an Amplifier of FceRly-Mediated Cell Activation Signals. Cell. 1996 Jun 28;85(7):985-95.

34. Miller KL, Duchemin AM, Anderson CL. A novel role for the Fc receptor $\mathrm{Y}$ subunit: Enhancement of FcyR ligand affinity. J Exp Med. 1996 May $1 ; 183(5): 2227-33$.

35. Fabiano Pinheiro da Silva. Caracterização da função dos receptores Fc de imunoglobulinas nas bacteremias. São Paulo. 2005. Tese apresentada na Faculdade de Medicina da USP.

36. Pasquier B, Launay P, Kanamaru Y, Moura IC, Pfirsch S, Ruffié C, Hénin D, Benhamou M, Pretolani M, Blank U, Monteiro RC. Identification of FcalphaRI as an inhibitory receptor that controls inflammation: dual role of FcRgamma ITAM. Immunity. 2005; 22(1):31-42. 
37. Pfirsch-Maisonnas S, Aloulou M, Xu T, Claver J, Kanamaru Y, Tiwari M, Launay $\mathrm{P}$, Monteiro RC, Blank $U$. Inhibitory ITAM signaling traps activating receptors with the phosphatase SHP-1 to form polarized "inhibisome" clusters. Sci Signal. 2011; 19;4(169):ra24.

38. Pinheiro da Silva F, Aloulou M, Skurnik D, Benhamou M, Andremont A, Velasco IT, Chiamolera M, Verbeek JS, Launay P, Monteiro RC. CD16 promotes Escherichia coli sepsis through an FcRg inhibitory pathway that prevents phagocytosis and facilitates inflammation. Nature Medicine. 2007; 1-7.

39. Aloulou M, Ben Mkaddem S, Biarnes-Pelicot M, Boussetta T, Souchet H, Rossato E, Benhamou M, Crestani B, Zhu Z, Blank U, Launay P, Monteiro RC. IgG1 and IVIg induce inhibitory ITAM signaling through FcyRIII controlling inflammatory responses. Blood. 2012 Mar 29;119(13):3084-96.

40. Gilfillan AM, Tkaczyk C. Integrated signalling pathways for mast-cell activation. Nat Rev Immunol. 2006 Mar;6(3):218-30.

41. Rivera J, Gilfillan AM. Molecular regulation of mast cell activation. J Allergy Clin Immunol. 2006 Jun;117(6):1214-25.

42. Kimberly RP, Salmon JE, Edberg JC. Receptors for immunoglobulin G. Molecular diversity and implications for disease. Arthritis Rheum. 1995; 38: 30614.

43. Selvaraj $P$, Rosse WF, Silber R, Springer TA. The major Fc receptor in blood has a phosphatidylinositol anchor and is deficient in paroxysmal nocturnal haemoglobinuria. Nature. 1988; 333: 565-7.

44. Gillis C, Gouel-Chéron A, Jönsson F, Bruhns P. Contribution of human FcyRs to disease with evidence from human polymorphisms and transgenic animal studies. Front Immunol. 2014 May 30;5:254.

45. Hill MJ, Drasar BS. The normal colonic bacterial flora. Gut. 1975 Apr 16(4):318-23.

46. Kaper JB, Nataro JP \& Mobley HL. Pathogenic Escherichia coli. Nat. Rev. Microbiol. 2004: 2:123-140.

47. Hacker J, Blum-Oehler G, Mühldorfer I, Tschäpe H. Pathogenicity islands of virulent bacteria: structure function and impact on microbial evolution. Mol Microbiol. 1997 Mar;23(6):1089-97. 
48. Sussman, M. Escherichia coli and human disease. In: Escherichia coli mechanisms of virulence. Cambridge. Reino Unido: University Press. 1997. Pg. 3-48.

49. Focaccia, RV. Tratado de Infectologia. Rio de Janeiro: Atheneu, 2005. p. 984-989

50. Murray PR, Rosenthal KS, Kobayashi GS, Pfaller MA. Microbiologia Médica. Rio de Janeiro: Guanabara Koogan, 2000. p. 207.

51. Schmitt CK, Meysick KC and O'Brien AD. Bacterial toxins: friends or foes? Emerg Infect Dis. 1999 Mar-Apr; 5(2): 224-234.

52. Smith GP. Filamentous fusion phage: novel expression vectors that display cloned antigens on the virion surface. Science. 1985 Jun $14 ; 228(4705): 1315-7$.

53. Benhar, I. Biotechnological applications of phage and cell display. Biotechnol Adv. 2001 Feb 1;19(1):1-33.

54. Azzazy HM, Highsmith WE Jr. Phage display technology: clinical applications and recent innovations. Clin Biochem. 2002 Sep;35(6):425-45.

55. Dias-Neto E, Nunes DN, Giordano RJ, Sun J, Botz GH, Yang K, Setubal JC, Pasqualini R. and Arap W. Next-generation phage display: integrating and comparing available molecular tools to enable cost-effective high-throughput analysis. PLoS One. 2009 Dec 17;4(12):e8338.

56. Russel M. Filamentous phage assembly. Mol Microbiol. 1991 Jul;5(7):1607-13.

57. Brígido MM e Maranhão AQ. Bibliotecas apresentadas em FAGOS. Biotecnologia, Ciência e Desenvolvimento. 2002 v. 26, p. 44-51.

58. Barbas CF, Burton DR, Scott JK, Silvermam GJ. Phage display. A laboratory Manual. Cold Spring Harbor Laboratory Press. 2001 p.8.4-8.7.

59. Smith GP, Petrenko VA. Phage display. Chem Rev. 1997 Apr $1 ; 97(2): 391-410$.

60. Huang JX, Bishop-Hurley SL, Cooper MA. Development of anti-infectives using phage display: biological agents against bacteria, viruses, and parasites. Antimicrob Agents Chemother. 2012 Sep;56(9):4569-82.

61. Mersich C, Jungbauer A. Generation of bioactive peptides by biological libraries. J Chromatogr B Analyt Technol Biomed Life Sci. 2008 Jan $15 ; 861(2): 160-70$. 
62. Greenwood J, Willis AE, Perham RN. Multiple display of foreign peptides on a filamentous bacteriophage. Peptides from Plasmodium falciparum circumsporozoite protein as antigens. J Mol Biol. 1991 Aug 20;220(4):821-7.

63. Noren KA, Noren CJ. Construction of high-complexity combinatorial phage display peptide libraries. Methods. $2001 \mathrm{Feb} ; 23(2): 169-78$.

64. Sergeeva A, Kolonin MG, Molldrem JJ, Pasqualini R, Arap W. Display technologies: application for the discovery of drug and gene delivery agents. Adv Drug Deliv Rev. 2006 Dec 30;58(15):1622-54.

65. Koivunen E, Gay DA., Ruoslahti E. Selection of peptides binding to the alpha 5 beta 1 integrin from phage display library. J Cell Biol. 1994 Feb;124(3):373-80.

66. Koivunen E, Arap W, Valtanen H, Rainisalo A, Medina OP, Heikkilä P, Kantor C, Gahmberg CG, Salo T, Konttinen YT, Sorsa T, Ruoslahti E, Pasqualini $R$ Tumor targeting with a selective gelatinase inhibitor. Nat Biotechnol. 1999 Aug;17(8):768-74.

67. Giordano RJ, Cardo-Vila M, Lahdenranta J, Pasqualini R, Arap W. Biopanning and rapid analysis of selective interactive ligands. Nat Med. 2001 Nov;7(11):1249-53.

68. Smith GP, Scott JK. Libraries of peptides and proteins displayed in filamentous phage. Methods Enzymol. 1993;217:228-57.

69. Pieper U, Webb BM, Barkan DT, Schneidman-Duhovny D, Schlessinger A, Braberg $H$, Yang Z, Meng EC, Pettersen EF, Huang CC, Datta RS, Sampathkumar P, Madhusudhan MS, Sjölander K, Ferrin TE, Burley SK, Sali A. ModBase, a database of annotated comparative protein structure models and associated resources. Nucleic Acids Res. 2011 Jan;39(Database issue):D46574.

70. Krieger E, Vriend G. YASARA View - molecular graphics for all devices from smartphones to workstations. Bioinformatics. 2014 Oct 15;30(20):2981-2.

71. Altschul SF, Gish W, Miller W, Myers EW, Lipman DJ. Basic local alignment search tool. J Mol Biol. 1990 Oct 5;215(3):403-10.

72. Vincent JL. Update on sepsis: pathophysiology and treatment. Acta Clin Belg. 2000; 55(2): p.79-87. 
73. Amulic B, Cazalet C, Hayes GL, Metzler KD, Zychlinsky A. Neutrophil Function: From Mechanisms to Disease. Annu. Rev. Immunol. 2012;30:459-89.

74. Flannagan RS, Jaumouillé V, Grinstein S. The cell biology os phagocytes. Annu Rev Pathol Mech Dis. 2012; 7:49-86.

75. Nordenfelt $\mathrm{P}$, Tapper $\mathrm{H}$. Phagossome dynamics during phagocytosis by neutrophils. J Leukoc Biol 2011; 90(2): 271-84.

76. Underhill DM, Ozinsky A. Phagocytosis of microbes: complexity in action. Annu Rev Immunol. 2002;20:825-52.

77. Aderem A, Underhill DM. Mechanisms of phagocytosis in macrophages. Annu Rev Immunol. 1999;17:593-623.

78. Marrack P, Kappler J. Subversion of the immune system by pathogens. Cell. 1994 Jan 28;76(2):323-32.

79. Blom AM, Hallström T, Riesbeck K. Complement evasion strategies of pathogens-acquisition of inhibitors and beyond. Mol Immunol. 2009 Sep;46(14):2808-17

80. Rautemaa R, Meri S. Complement-resistance mechanisms of bacteria. Microbes Infect. 1999 Aug;1(10):785-94.

81. Li S, Ojcius DM, Liao S, Li L, Xue F, Dong H, Yan J. Replication or death: distinct fates of pathogenic Leptospira strain Lai within macrophages of human or mouse origin. Innate Immun. 2010 Apr;16(2):80-92. doi: 10.1177/1753425909105580. Epub 2009 Jul 8.

82. Falcao JP, Falcao DP. Importância de Yersinia enterocolítica em Microbiologia Médica. Rev. Ciên. Farm. Básica Apl. 2006; 27(1):9-19.

83. Celli J, Olivier M, Finlay BB. Enteropathogenic Escherichia coli mediates antiphagocytosis through the inhibition of PI 3-kinase-dependent pathways. EMBO J. 2001 Mar 15;20(6):1245-58.

84. Mota LJ, Sorg I, Cornelis GR. Type III secretion: The bacteria-eukaryotic express. FEMS Microbiology Letters. 2005;252:1-10.

85. Goosney DL, Celli J, Kenny B, Finlay BB. Enteropathogenic Escherichia coli inhibits phagocytosis. Infect Immun. 1999 Feb;67(2):490-5.

86. Dean P, Maresca M, Kenny B. EPEC's weapon of mass subversion. Curr Opin Microbiol. 2005;8:28-34. 
87. MacDaniel TK, Jarvis KG, Donnenberg MS, Kaper JB. A genetic locus of enterocyte effacement conserved among diverse enterobacterial pathogens. Proc Natl Acad Sci USA. 1995;92:1664-8.

88. Russell DG. Mycobacterium tuberculosis: here today, and here tomorrow. Nat Rev Mol Cell Biol. 2001 Aug;2(8):569-77. Review.

89. Santamaria H. Manoutcharian K, Rocha L, Gonzalez E, Acero G, Govezensky T, Uribe LI, Olguin A, Paniagua J, Gevorkian G. Identification of peptide sequences specific for sérum antibodies frm Papillomavirus infected patients using Phage Libraries. Clin Immunol. 2001 Dec;101(3):296-302.

90. Du B, Qian M, Zhou Z, Wang P, Wang L, Zhang X, Wu M, Zhang P, Mei $B$. In vitro panning of a targeting peptide to hepatocarcinoma from a phage display peptide library. Biochem Biophys Res Commun. 342(3):956-962, 2006.

91. Hu S, Guo X, Xie H, Du Y, Pan Y, Shi Y, Wang J, Hong L, Han S, Zhang D, Huang D, Zhang K, Bai F, Jiang H, Zhai H, Nie Y, Wu K, Fan D. Phage display selection of peptides that inhibit metastasis ability of gastric câncer cells with high liver-metastatic potential. Biochem Biophys Res Commun. 2006 Mar 24;341(4):964-72.

92. Parhami-Seren B, Krudysz J, Tsantili P.. Affinity pnning of peptide libraries using anti-streptokinase monoclonal antibodies: selection of an inhibitor os plasmin(ogen) active site. J Immunol Methods. 2002 Sep 15;267(2):185-98.

93. Cardellini E, Felici F, Gianfranceschi GL. Identification of peptides mimicking the ligands of proteins phosphorylated by protein kinase CK2. Peptides. 2004 Feb;25(2):191-7.

94. Gnanasekar M, Padmavathi B, Ramaswamy K. Cloning and characterization of a novel immunogenic protein 3 (NIP3) from Brugia malayi by immune screening of a phage-display cDNA expression library. Parasitol Res. 2005 Aug;97(1):49-58.

95. André S, Arnusch CJ, Kuwabara I, Russwurm R, Kaltner H, Gabius HJ, Pieters RJ. Identification os peptide ligands for malignancy- and growth0 regulating galectins using random phage display and designed combinatorial peptide libraries. Bioorg Med Chem. 2005 Jan 17;13(2):563-73.

96. Lang J, Zhan J, Xu L, Yan Z. Identification of peptide mimetics of xenoreactive a-Gal antigenic epitope by phage display. Biochem Biophys Res Commun. 2006 May 26;344(1):214-20.

97. Buchwald UK, Lees A, Steinitz M, Pirofski LA. A peptide mimetope of type 8 pneumococcal capsular polysaccharide induces a protective immune responde in mice. Infect Immun. 2005 Jan;73(1):325-33. 
98. Petsch D, Anspach FB. Endotoxin removal from protein solutions. $J$ Biotechnol. 2000 Jan 21;76(2-3):97-119.

99. Gorbet MB, Sefton MV. Endotoxin: the uninvited guest. Biomaterials. 2005 Dec;26(34):6811-7.

100. Marolda CL, Vicarioli J, Valvano MA. Wzx proteins involved in biosynthesis of $\mathrm{O}$ antigen function in association with the first sugar of the $\mathrm{O}$ specific lipopolysaccharide subunit. Microbiology. 2004 Dec;150(Pt 12):4095105.

101. Rietschel ET, Brade H, Holst O, Brade L, Muller-Loennies S, Mamat U, et al. Bacterial endotoxin: Chemical constitution, biological recognition, host response, and immunological detoxification. Curr Top Microbiol Immunol. 1996;216:39-81.

102. DebRoy C, Roberts E, Fratamico PM.Detection of $O$ antigens in Escherichia coli. Anim Health Res Rev. 2011 Dec;12(2):169-85.

103. Valvano MA. Export of O-specific lipopolysaccharide. Front Biosci. 2003 May 1;8:s452-71.

104. Hong Y, Reeves PR. Diversity of o-antigen repeat unit structures can account for the substantial sequence variation of wzx translocases. J Bacteriol. 2014 May;196(9):1713-22.

105. Islam ST, Lam JS. Synthesis of bacterial polysaccharides via the Wzx/Wzy-dependent pathway. Can J Microbiol. 2014 Nov;60(11):697-716.

106. Islam ST, Eckford PD, Jones ML, Nugent T, Bear CE, Vogel C, Lam JS. Proton-dependent gating and proton uptake by Wzx support O-antigen-subunit antiport across the bacterial inner membrane. MBio. 2013 Sep 10;4(5):e0067813.

107. Rick PD, Barr K, Sankaran K, Kajimura J, Rush JS, Waechter CJ. Evidence that the wzxE gene of Escherichia coli $\mathrm{K}-12$ encodes a protein involved in the transbilayer movement of a trisaccharide-lipid intermediate in the assembly of enterobacterial common antigen. J Biol Chem. 2003 May 9;278(19):16534-42.

108. Kajimura J, Rahman A, Rick PD. Assembly of cyclic enterobacterial common antigen in Escherichia coli K-12. J Bacteriol. 2005 Oct;187(20):691727.

109. Marolda CL, Tatar LD, Alaimo C, Aebi M, Valvano MA. Interplay of the Wzx translocase and the corresponding polymerase and chain length regulator proteins in the translocation and periplasmic assembly of lipopolysaccharide 0 antigen. J Bacteriol. 2006 Jul;188(14):5124-35. 